\title{
A 3D Finite Element Model of Rolling Contact Fatigue for Evolved Material Response and Residual Stress Estimation
}

\author{
Muhammad U Abdullah ${ }^{1} \cdot$ Zulfiqar A Khan $^{1}$ (D) $\cdot$ Wolfram Kruhoeffer ${ }^{2} \cdot$ Toni Blass $^{2}$
}

Received: 10 June 2020 / Accepted: 18 October 2020 / Published online: 4 November 2020

(c) The Author(s) 2020

\begin{abstract}
Rolling bearing elements develop structural changes during rolling contact fatigue (RCF) along with the non-proportional stress histories, evolved residual stresses and extensive work hardening. Considerable work has been reported in the past few decades to model bearing material hardening response under RCF; however, they are mainly based on torsion testing or uniaxial compression testing data. An effort has been made here to model the RCF loading on a standard AISI 52100 bearing steel with the help of a 3D Finite Element Model (FEM) which employs a semi-empirical approach to mimic the material hardening response evolved during cyclic loadings. Standard bearing balls were tested in a rotary tribometer where pure rolling cycles were simulated in a 4-ball configuration. The localised material properties were derived from post-experimental subsurface analysis with the help of nanoindentation in conjunction with the expanding cavity model. These constitutive properties were used as input cyclic hardening parameters for FEM. Simulation results have revealed that the simplistic power-law hardening model based on monotonic compression test underpredicts the residual generation, whereas the semiempirical approach employed in current study corroborated well with the experimental findings from current research work as well as literature cited. The presence of high compressive residual stresses, evolved over millions of RCF cycles, showed a significant reduction of maximum Mises stress, predicting significant improvement in fatigue life. Moreover, the predicted evolved flow stresses are comparable with the progression of subsurface structural changes and be extended to develop numerical models for microstructural alterations.
\end{abstract}

Zulfiqar A Khan

zkhan@bournemouth.ac.uk

1 Bournemouth University, Department of Design \&

Engineering, NanoCorr, Energy \& Modelling (NCEM)

Research Group, Poole, Dorset, United Kingdom

2 Schaeffler Technologies AG \& Co. KG, Herzogenaurach,

Germany 


\section{Graphic Abstract}
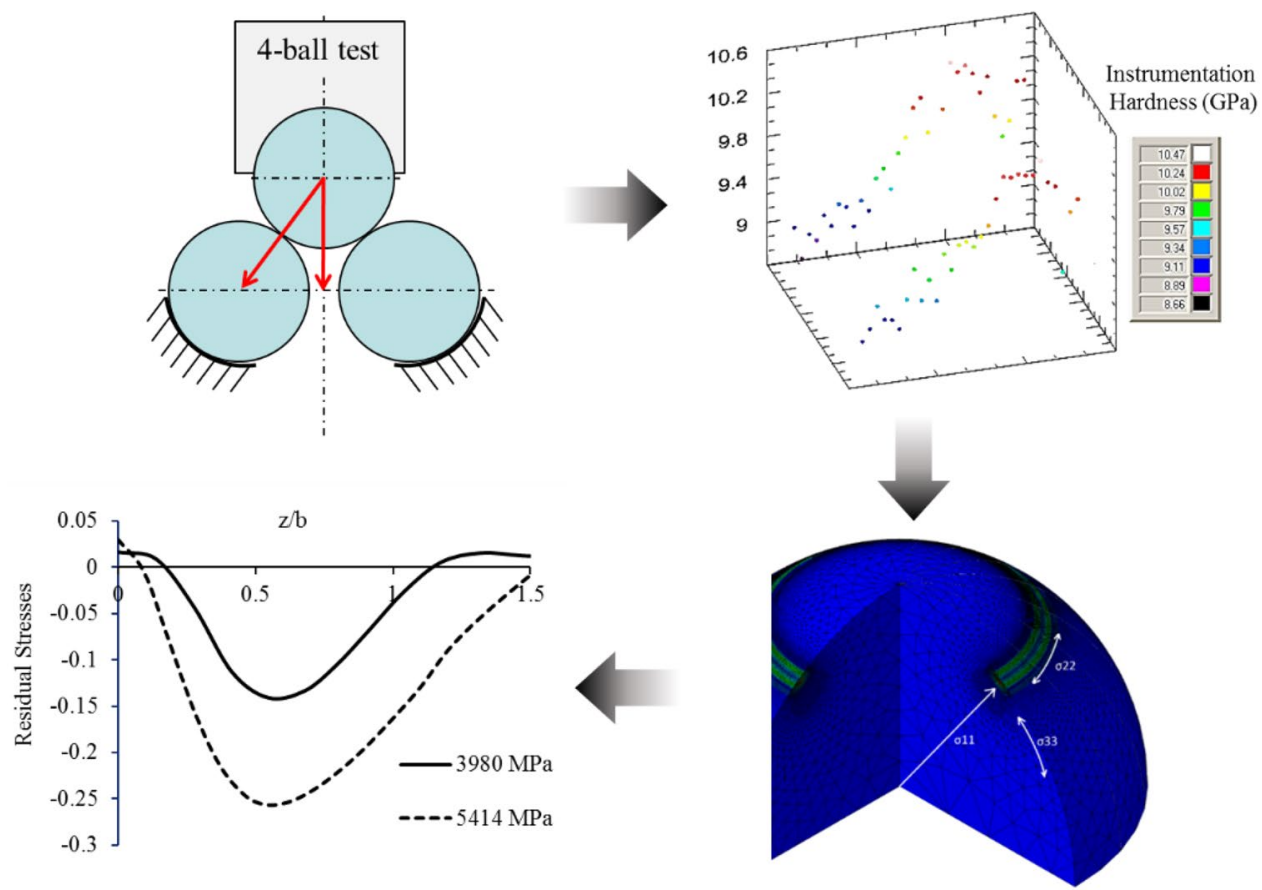

Keywords Rolling bearing elements $\cdot$ FE model $\cdot$ Fatigue life $\cdot$ Residual stresses

\section{Abbreviations}

$\mathrm{P}_{\max } \quad$ Maximum Hertzian Pressure

$\sigma_{\mathrm{y}} \quad$ Yield/flow stress

$\mathrm{n} \quad$ Strain hardening index

F Axial load

$\mathrm{F}_{\mathrm{R}} \quad$ Resultant/Normal load

$\mathrm{H}_{\mathrm{IT}} \quad$ Instrumentation hardness

A Area of Indenter

HV Vickers hardness

$\alpha \quad$ Effective cone angle

E Young Modulus

S Stress vector

$q \quad$ Back stress

$\varepsilon_{p l}^{-} \quad$ Accumulated plastic strains

$\sigma_{y}^{o} \quad$ Instantaneous yield strength

Q Isotropic hardening

z/b Normalised centreline depth

$\beta \quad$ Rate of isotropic expansion

$q^{\prime} \quad$ Increment in back stress

C Initial kinematic modulus

$\gamma \quad$ Rate of decreasing $\mathrm{C}$

$(\Delta \sigma y)_{\max }$ Maximum change in yield surface

NIKH Non-linear isotropic kinematic hardening

z Centreline depth from contact track

$\mathrm{S}_{12} \quad$ Orthogonal shear stress

PEEQ Equivalent plastic strains a Semi-major axis

b Semi-minor axis

$\sigma_{22} \quad$ Residual stress in circumferential direction

RS Mises residual stress

$\mathrm{S}_{\max } \quad$ Maximum amplitude of alternating stress

$\mathrm{S}_{\min } \quad$ Minimum amplitude of alternating stress

\section{Introduction}

Rolling element bearings are designed to enable smooth rotation during service. Severe loadings, starved lubrication condition and dynamic loadings cause detrimental effects on bearing life [1]. Stress histories in a bearing element during rolling cycles are termed rolling contact fatigue (RCF). The two regimes of fatigue high cyclic fatigue and low cyclic fatigue are distinguished due to the number of running cycles required for failure and the rate of irreversible plastic flow which accumulates with corresponding stress cycles. $\mathrm{RCF}$ is, however, different from the conventional low cyclic and high cyclic fatigue due to complex multiaxial nature and non-proportional loading [2]. Typically in a rolling bearing element, carbide volume fraction, retained austenite, microtexture, microstructure and deep zone residual stresses with non-proportional cyclic stress histories make bearing material heterogeneous in nature [3]. A generic representation of 
a typical bearing life exhibits three phases of microstructural changes and residual stress evolution during RCF loading starting from initial plastic shakedown (stage I) to steadystate response (stage II) which is followed by the instability (stage III) leading to bearing failure [4]. Initial plastic shakedown refers to the initial accumulation of plasticity during RCF cycles; afterwards, there is little to no further plasticity generation and bearing operates mostly in the elastic regime.

According to Hertzian contact theory, the maximum pressure $\left(\mathrm{P}_{\max }\right)$ required to cause plastic yielding of a subsurface material point with a static contact load is given by $\mathrm{P}_{\max }=$ $1.6 \sigma_{y}$, where $\sigma_{y}$ is the yield strength of the virgin material [5]. Rolling bearing elements are typically operated in $<2.5$ GPa pressure so the loading response of the material remains globally elastic. However, at microstructural level, the local stress concentration due to carbides and non-metallic inclusions causes subsurface plasticity, also named microplasticity [6]. However, the range of plasticity accumulation $\left(\Delta \varepsilon_{\mathrm{p}}\right)$ with progressive RCF cycle beyond the shakedown limit is minimal, i.e. in the range of $\Delta \varepsilon_{\mathrm{p}}<0.003$ and is spread over a wide range, i.e. $\sim 10^{10}$ cycles [7]. During this steady-state stage, the microstructure of the stressed zone under Hertzian contact evolves gradually, which causes material phase transformation, changes in residual stresses and change in yield strength unceasingly. The ability of the material to work harden under such conditions is quite significant and the spatial and temporal evolution of this hardness change is very critical for damage accumulation as hardness change defines the material resistance to plastic flow. The continuously evolving cyclic stress-strain fields under the influence of residual stresses makes complexities in modelling rolling contact fatigue. Despite the wide usage of high strength bearing steels, limited information on material hardening is available for standard AISI 52100 bearing steel only under monotonic tension and compression loading and static torsional loading [7] which cannot address the true micromechanical response of bearing material operated under triaxial loading in RCF. Due to the absence of relevant material hardening data, it is quite challenging to undertake realistic studies on RCF-induced damage evaluation and resulting residual stress estimation.

The residual stresses during RCF arise due to non-uniform volume expansion (decomposition of retained austenite) and non-uniform plasticity due to complex subsurface stress state. Deep zone residual stresses formed during cyclic loading ranging from $3 b$ to $9 \mathrm{~b}$ contact depth play a vital role in bearing life [8], where $b$ represents the semi-minor axis. Residual stresses are especially valuable when employed with higher strength metals. It has been reported [9-11] that the fatigue life of a bearing element can be improved with the help of compressive residual stresses (CRS). These compressive residual stresses significantly affect fatigue life by crack closure and hindering crack growth $[11,12]$.
Moreover, it also alters the alternating applied stress range which governs the fatigue life of bearing material. These residual stresses can be decreased or totally lost by stress relaxation which is associated with the cyclic yielding and higher strain amplitude. However, at very small strain amplitude (during steady-state stage), the relaxation ceases at stable value [13, 14]. Voskamp [9], after endurance testing of deep groove ball bearings (DGBB), reported onset and progressive change in residual stresses and structural alterations with rolling cycles. The gradual structural alterations have been termed Dark Etching regions (DERs) and White Etching bands (WEBs) $[2,15,16]$ owing to decomposition of retained austenite and parent martensite. Later experimental studies $[10,17,18]$ on ball bearings owing to rolling contact fatigue showed significant contribution of deep zone residual stresses towards bearing failure. Moreover, researchers $[19,20]$ have reported that a close proximity exists between residual stress distribution with subsurface microstructural alterations; however, the assessment of residual stresses during subsurface alterations along with plasticity accumulation has not been evaluated.

A realistic finite element model to RCF requires prior knowledge of cyclic response of material along with a reliable material model. As discussed earlier, during rolling contact fatigue, material undergoes cyclic plasticity which is accumulated at subsurface level over hundreds of million cycles along with the kinematic translation and radial expansion of yield surface. It is reported [21, 22] that the plastic strain accumulation during RCF cycles results in contact track widening and change in contact geometry. Previous research studies [5, 22-26] employed the power-law hardening model and elastic linear kinematic hardening plastic (ELKP) model where the hardening parameters were derived from uniaxial compression test or torsional test of standard bearing steel. These models described the plastic distortion, cyclic plastic strains and residual stresses in early life (RCF cycle $<10^{6}$ ) of a bearing in good agreement with the experimental data. However, it under-predicted the residual stresses in the later life (RCF cycles $>10^{6}$ ) of a bearing element, as reported by Bush [27] and Voskamp [9]. Besides, these conventional models failed to incorporate the stochastic nature of the bearing material due to cyclic yielding during RCF which needed to be defined with a more complex and sophisticated hardening model.

The non-linear isotropic and kinematic hardening (NIKH) model was presented by Chaboche and Lamaitre to study the cyclic response of material under multiaxial fatigue [28]. The NIKH model is capable of simulating complex material behaviour during RCF loading, i.e. plastic shakedown, cyclic hardening, and ratcheting in the steady-state regime of RCF cycles [29]. It has been reported [30] that the ratcheting based response of the bearing material microstructure can be modelled with the help of non-linear kinematic hardening 
response. Nevertheless, the initial response of the bearing in the early stage is best represented by the combined effect of isotropic expansion and kinematic expansion. Current study also employs the combined isotropic and non-linear kinematic hardening model with the combination of nanohardness measurement. The reason for opting such material behaviour is to successfully model the initial plastic shakedown along with the ratcheting behaviour of bearing material. The material constants required for NIKH material model can be derived with the help of expanding cavity model presented by Gao et al. [31]. The expanding cavity model describes the indentation deformation of elastic power-law hardening and elastic linear hardening materials and reported that, for given indenter geometry, indentation hardness depends on Young's Modulus, yield stress and strain hardening index ' $n$ ' of the indented surface. Earlier studies [32, 33] have employed micro-indentation experiments on RCF damage evaluation and reported a gradual increase in material hardness with the linear accumulation of plastic strains. However, they were unable to evaluate the very localised damage of the RCF damaged zone due to the limitation of micro-indenter that only gives an average hardness over the grain [34]. Current research work overcomes that problem with the use of a Berkovich nanoindenter. The use of three-faced pyramidal Berkovich indenter having the same depth-to-area ratio as a Vickers indenter made it convenient to measure accurately the change in hardness of the RCF-affected zone. The precise temporal and spatial evaluation of this hardness change due to RCF-induced damage resulted in cyclically evolved yield stress which can be used to estimate the cyclic hardening parameters for NIKH material model. The resulting model can accurately capture the evolved elastoplastic response of the material in the later life of RCF loading and resulting residual stresses can be assessed.

The following sections describe RCF experiments with a ball-on-ball rolling contact in a rotary tribometer which was followed by surface/subsurface investigations. Next, development of a 3D finite element model for RCF is presented. The material model relies on the constitutive response of the bearing material after RCF testing. The constitutive response is based on the cyclic hardening parameters obtained from nanoindentation in conjunction with expanding cavity model. Simulation results showed a significant difference in estimation of deep zone residual stresses employing newly developed semi-empirical material model when compared with the conventional uniaxial power-law hardening in the later life of rolling cycles.

\section{RCF Experimentation}

A high-speed Microprocessor Rotary Tribometer (TE-92) with 4-ball configuration was employed to run the RCF test on through-hardened AISI 52100 bearing steel balls of
$12.7 \mathrm{~mm}$ diameter. In this configuration, three lower balls are kept in a cup which acts as outer race of the bearing. The upper ball is mounted on a shaft with the help of a collet and rotates on top of lower three balls which forms a contact track similar to the inner raceway of a bearing $[35,36]$, following Fig. 1. Industrial grade ISO-VG-320 (kinematic viscosity of $300 \mathrm{cSt}$ at $40{ }^{\circ} \mathrm{C}$ ) was used as a lubricant to avoid asperity contacts so that pure subsurface damage can be evaluated with no contact track wear. The cleanliness of the added lubricant in the lower cup and calculated lambda ratios (described in section Appendix) ensured no wear phenomenon during the test. Tests were carried out with two different load levels at the spindle with $40{ }^{\circ} \mathrm{C}$ lubricant temperature which was kept constant throughout experiments. Tests were stopped either at required RCF cycles or whenever a ball fails due to spalling which was detected by a vibration cut-off sensor. Schematic for 4-ball configuration is shown in Fig. 1 and conducted experiments are listed in Table 1. After experimentation, samples were sliced and then polished with diamond suspension to make the sample suitable for nanoindentation. A 3\% Nital solution (97\% Ethanol, 3\% Nitric acid) was also used later on to reveal the surface as an etchant. A uniaxial compression test was also carried out to obtain the flow curve of the bearing material with similar composition as of RCF-tested samples. The stress-strain curve is plotted in Fig. 2 and corresponding material properties are referred in Sect. 2.2 for subsurface hardness evaluation.

The 4-ball kinematics is described as the upper ball (with radius $6.35 \mathrm{~mm}$ ) rotates on top of lower three balls having same radius, the upper ball in collet undergoes 2.25 times stress cycle and develops a contact track which continues to grow with respective stress cycles. This contact track was investigated with the help of a 3D optical interferometer for each sample during RCF test. The samples were cleaned with the ultrasonic cleaner to remove any lubrication prior to interferometry and measurements were taken after specified running cycles. A typical interferometer analysis is shown in Fig. 1. The consistency and repeatability of the contact track measurements indicate the reliability of the acquired data.

\subsection{Hardness Measurement}

Subsurface hardness was evaluated for the virgin material with a Vickers Indenter (HV 0.3). For through-hardened bearing steel, it was expected to be nearly constant over entire depth. After RCF experimentation, samples were sliced in a plane parallel to contact track, see Fig. 1, and polished with a final diamond suspension spray of $0.5 \mu \mathrm{m}$ particle size to remove unwanted surface roughness. For nanoindentation, a 3-faced pyramidal Berkovich Indenter was used which measures the indentation hardness $\left(\mathrm{H}_{\mathrm{IT}}\right)$ as a function of load-displacement curve. The indentation 


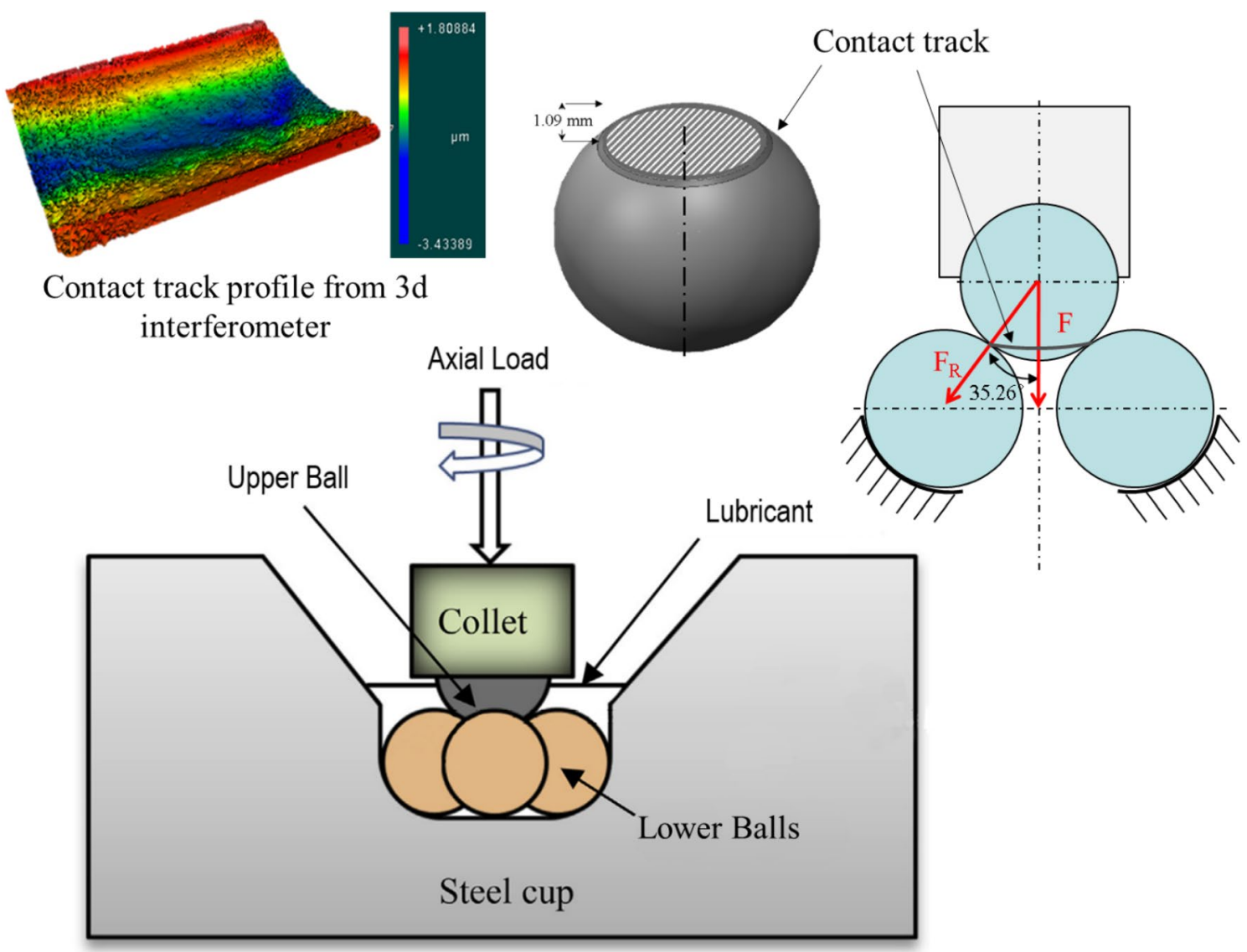

Fig. 1 Four-ball test configuration shown with 12.7-mm-diameter bearing balls; contact track profile is shown in the left top corner. Post-RCFtested sample sliced in the circumferential direction (parallel to contact track) for subsurface analysis

Table 1 Four-ball experiments conducted for RCF test under high and low load conditions

\begin{tabular}{llllll}
\hline Axial load $(\mathrm{F})$ & $\begin{array}{l}\text { Resultant/normal } \\
\text { load }\left(\mathrm{F}_{\mathrm{R}}\right)\end{array}$ & $\begin{array}{l}\text { Hertzian contact } \\
\text { stress }\end{array}$ & $\begin{array}{l}\text { Operating tem- } \\
\text { perature }\end{array}$ & RCF speed & $\begin{array}{l}\text { Run cycles } \\
\text { (in million) }\end{array}$ \\
\hline $\begin{array}{l}2.1 \mathrm{kN} \\
(\mathrm{High} \text { load) }\end{array}$ & $857 \mathrm{~N}$ & $6.02 \mathrm{GPa}$ & $40^{\circ} \mathrm{C}$ & $4300 \mathrm{rpm}$ & 0.375 \\
$650 \mathrm{~N}$ & & & $40{ }^{\circ} \mathrm{C}$ & $4300 \mathrm{rpm}$ & 42.75 \\
$($ Low load) & $265 \mathrm{~N}$ & $4.07 \mathrm{GPa}$ & $40{ }^{\circ} \mathrm{C}$ & $4300 \mathrm{rpm}$ & 0.375 \\
\hline
\end{tabular}

hardness (also known as Instrumentation hardness) is defined by the applied load $(F)$ divided by the projected area of indent $(A)$ as

$H_{I T}=\frac{F}{A\left(h_{c}\right)}$.

The projected area of indent is a function of contact depth $\left(h_{c}\right)$ and is calculated from the knowledge of indenter geometry and stiffness of the contact. To determine the projected area function of a typical Berkovich indenter, a reference sample with known elastic modulus is indented and a relationship is obtained between contact depth and projected area. Further details of area function analysis are described in section Appendix.

The load-unload curve from nanoindentation is fitted to power-law fit and contact compliance and plastic depth $\left(h_{c}\right)$ is calculated using Oliver and Pharr analysis [37]. Once the plastic depth is computed, the instrumented hardness can be obtained in GPa from equation (1). From ISO 14577-1:2015, the ratio of surface area to projected area is kept constant for a perfect Vickers or modified Berkovich indenter, which leads to the correlation of indentation hardness with the conventional Vickers hardness as 


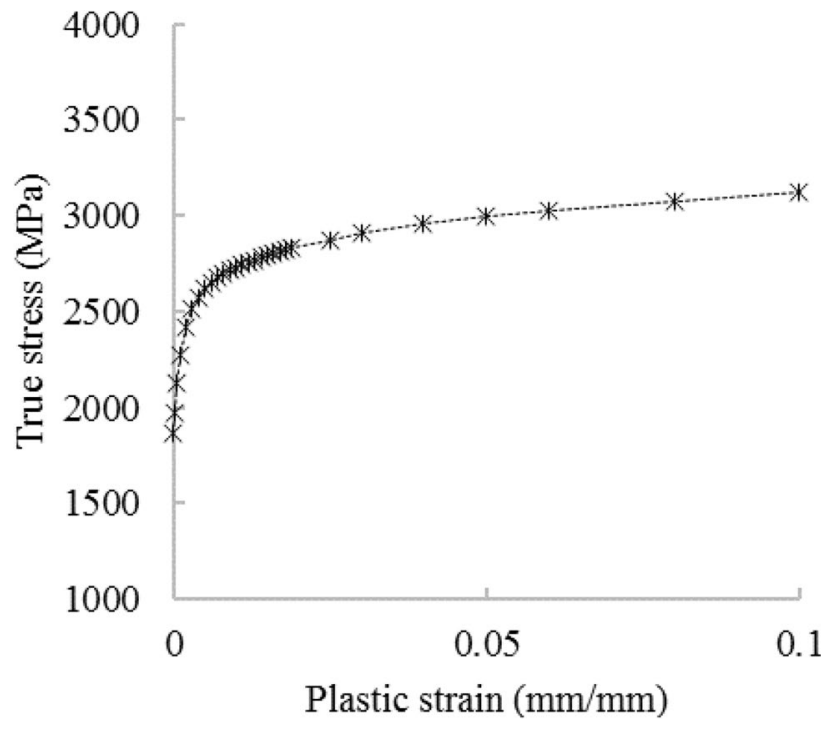

Fig. 2 Flow curve obtained from the compression test of bearing steel at room temperature with similar composition as RCF-tested samples

$H V=0.0945 \times H_{I T}($ in $M P a)$.

The instrumentation hardness obtained from the nanoindentation test for each sample can be converted in Vickers hardness scale. Fig. 3a reveals the Nital-etched microstructure after $6 \mathrm{GPa}$ test and Fig. 3b represents nanoindentation performed in rows from the surface towards the core of sample. The applied load is kept constant in each row of indent and corresponding instrumentation hardness is evaluated from equation (1) and (2). Fig. 3c shows the nanoscale measured hardness in $\mathrm{H}_{\mathrm{IT}}$ and respective estimated Vickers hardness (HV) for both samples. For comparison of the converted hardness scale, an HV0.3 hardness profile is also plotted which shows consistent hardness response from virgin ball bearing sample. It is evident that the baseline hardness for the nanoindentation profiles can be marked near 9.01 $\pm 0.1 \mathrm{GPa}(\sim 853 \mathrm{HV}$ in converted scale) which is reasonably in range with the measured HV0.3 values. It has been observed that changing the nanoindentation load greatly affects the observed hardness where the baseline hardness shifts its position. In order to compensate the size effect of applied load, the nanoindentations were conducted with applied loads of 100, 50 and $10 \mathrm{mN}$ and series of tests were carried out to check the repeatability and reliability of the measured hardness.

Considerable microstructural alterations (Dark etching regions, DERs) can be observed under the contact track, marked as RCF-affected zone in Fig. 3a. Such microstructural alterations are attributed to the decay of parent structure due to the subsurface plastic deformation during high cyclic loadings which accumulates over millions of RCF cycles [9]. The associated bearing material response can be characterised by an increase in highly localised hardness with reference to the observed baseline hardness. No observable change in the microstructure was obtained for $4 \mathrm{GP}$ tested sample; however, a slight change in subsurface hardness can be observed.

For elastic power-law hardening materials, Gao [31] presented an expanding cavity model which correlates the material hardness with elastic modulus and flow stress as

$\frac{H}{\sigma_{y}}=\frac{2}{3}\left\{\left(1-\frac{1}{n}\right)+\left(\frac{3}{4}+\frac{1}{n}\right)\left(\frac{1}{3} \frac{E}{\sigma_{y}} \operatorname{Cot} \alpha\right)^{n}\right\}$,

where ' $\mathrm{H}$ ' represents hardness in $\mathrm{MPa}$, ' $\mathrm{n}$ ' is strain hardening exponent, derived from monotonic compression test, Young's Modulus $\mathrm{E}=210 \mathrm{GPa}$ and ' $\alpha$ ' is effective cone angle ( $\alpha=70.2996^{\circ}$ for Berkovich Indenter).

The highly localised nanoindentation hardness estimated in Vickers hardness scale can be transformed into evolved flow stress of the material using equation (3). As discussed earlier, expanding cavity model works well with the strain hardening materials, so an appropriate value of strain hardening exponent was derived from uniaxial compression test (see Fig. 2), and corresponding flow stresses were evaluated under the contact track. Maximum evolved flow stress obtained at $155 \mu \mathrm{m}$ below contact path was $2967 \mathrm{MPa}$ $\left(\mathrm{H}_{\mathrm{IT}}=10.47 \mathrm{GPa}\right)$, which corresponded to a total hardness increase of $\sim 417 \mathrm{MPa}(2967-2550=417 \mathrm{MPa})$. This 417 $\mathrm{MPa}$ flow stress was evolved during RCF loading at $6 \mathrm{GPa}$ contact stress after 42.75 million RCF cycles. This increase in hardness is in comparison with the previous studies [33, 38] where substantial hardening of subsurface region during RCF loading was reported. The precise measurement of change in hardness for RCF sample tested at $4 \mathrm{GPa}$ contact stress also reported an increase of hardness (i.e. 9.91 GPa) at $95 \mu \mathrm{m}$ depth with reference to the baseline hardness. This RCF-affected evolved flow stresses represent the evolved yield stress of the subsurface in the later life rolling cycles and can be used as an input parameter for the finite element model.

\section{Finite Element Modelling}

To simulate the RCF loading of a 4-ball test, a 3D finite element model, shown in Fig. 4, has been developed in a commercial solver Abaqus. The model comprises of a deformable sphere with rigid plates rotating over the contact track where the whole model was designed to the original scale. A 4-node linear hexahedral element type has been used to model the entire contact track with relatively finer mesh size, while the rest of the geometry was meshed with quadratic tetrahedral elements. Use of cyclic symmetric model, rigid surfaces and optimised mesh element size (5 um for 


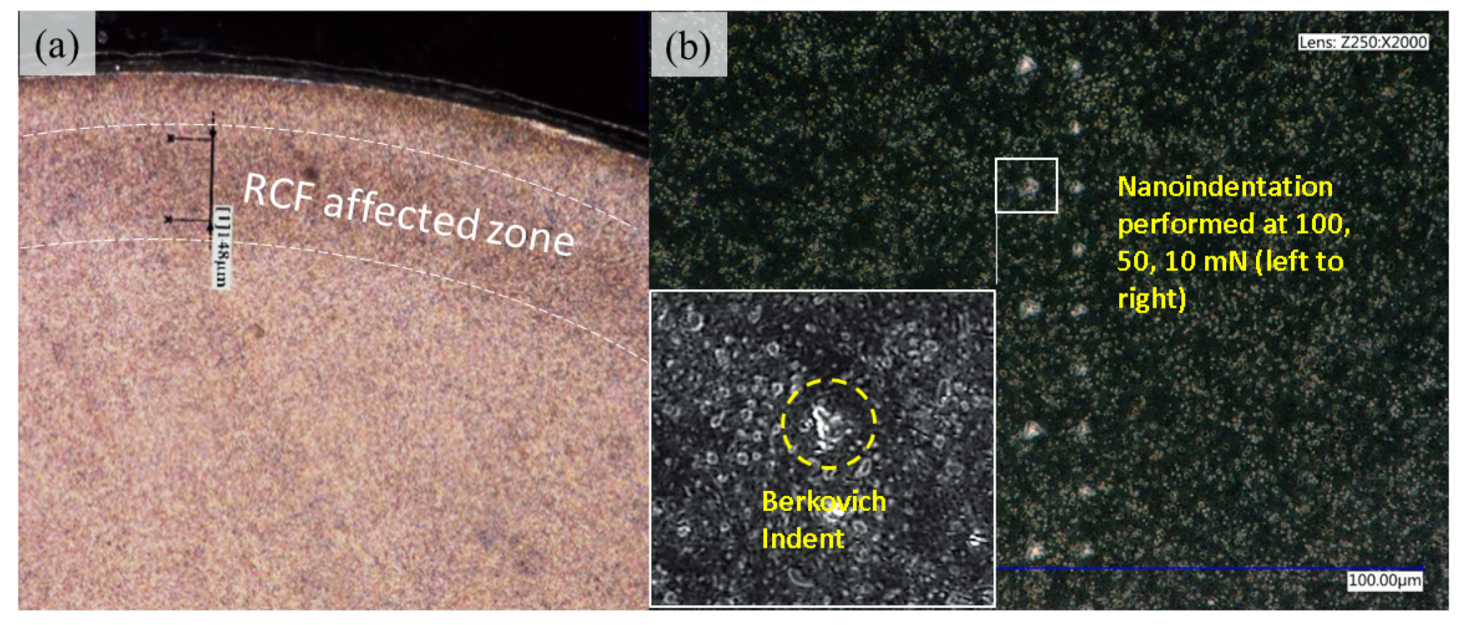

(c)

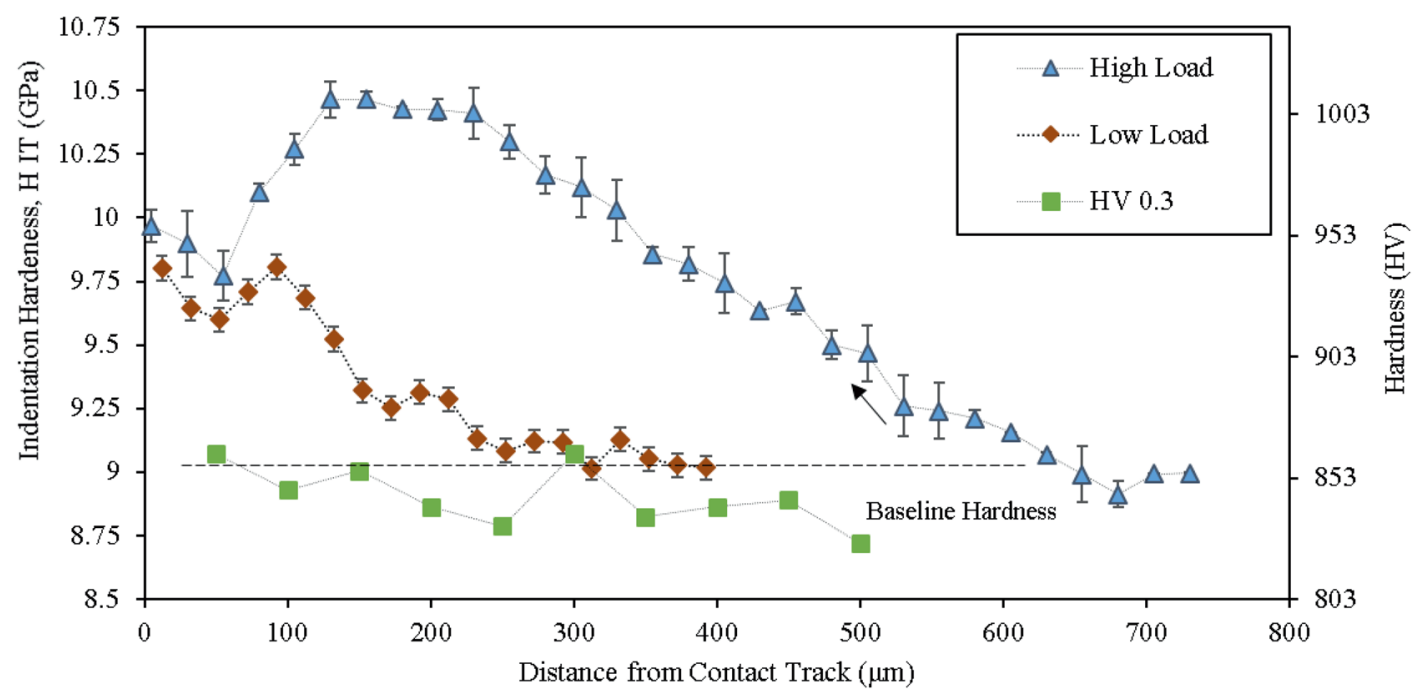

Fig. 3 Subsurface investigation of axially sliced RCF-tested samples: (a) Nital-etched sample after 42.7 million RCF cycles at $6 \mathrm{GPa}$ contact stress, (b) nanoindentation performed at 100, 50 and $10 \mathrm{mN}$;

hexahedral brick element) made the model possible to solve with higher accuracy and less computational time. The load was applied at an angle of $35.26^{\circ}$ with the vertical axis (as demonstrated in Fig. 1) and was ramped during multiple cycles so that stresses can be stabilised and smoothly distributed across the contact track. For interacting bodies, a surface to surface contact pair was defined with a frictionless contact.

The non-linear kinematic isotropic material model was employed to mimic the cyclic response of AISI 52100 bearing steel. This model is based on two types of material behaviour, i.e. an isotropic part which causes the yield surface of material to expand and a non-linear kinematic part which causes the yield surface to translate with a back stress. The model is based on von Mises or maximum distortion energy yield criterion. The generalised associative flow [28] is given as zoomed-in area represents Berkovich indent lies in the vicinity of carbides, (c) indentation hardness $\mathrm{H}_{\mathrm{IT}}$, plotted for both RCF-tested samples along with reference virgin material hardness HV0.3

$f\left(\mathrm{~S}, \mathrm{q}, \varepsilon_{p l}^{-}\right)=|S-q|-\sigma_{y}$,

where ' $\mathrm{S}$ ' is the stress vector, ' $\mathrm{q}$ ' is the back-stress tensor, ' $\varepsilon_{p l}^{-\prime}$ is the accumulated plastic strains and ' $\sigma_{\mathrm{y}}$ ' is the instantaneous yield strength. For non-linear isotropic hardening, this instantaneous yield strength will be

$\sigma_{y}=\sigma_{y}^{o}+Q\left(1-e^{-\beta \varepsilon_{p l}^{-}}\right)$.

Here ' $\sigma_{y}^{o}$ ' is initial yield strength of the material, and ' $Q$ ' represents the maximum expansion of yield surface with rate ' $\beta$ '. For non-linear kinematic hardening,

$q^{\prime}=\frac{2}{3} C \varepsilon_{p l}^{\cdot}-\gamma \varepsilon_{p l}^{-}$, 
Fig. 4 FE Model for simulating rolling contact fatigue in a 4-ball test

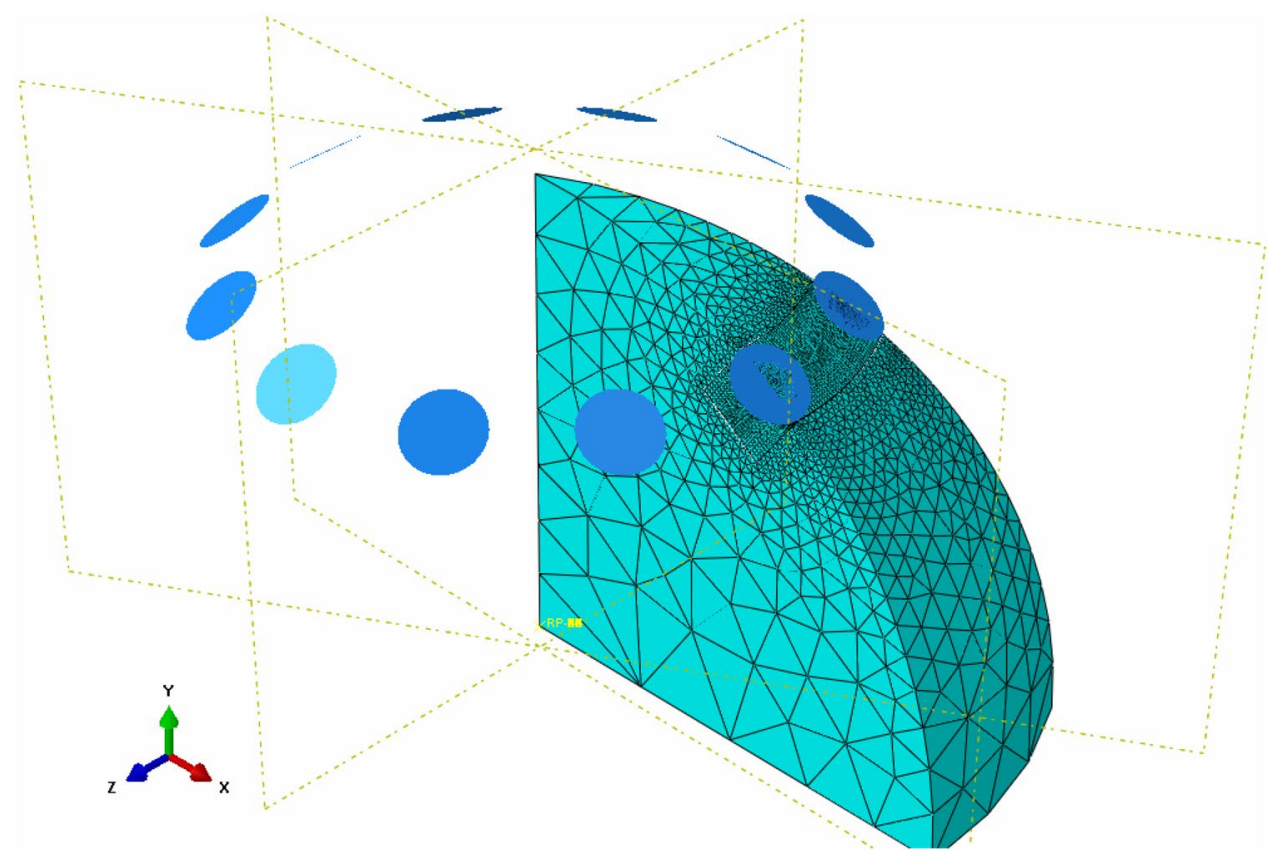

where ' $q$ ' denotes increment in back-stress tensor, ' $C$ ' is initial kinematic hardening modulus, ' $\gamma$ ' is rate of decreasing ' $\mathrm{C}$ ' and ' $\varepsilon_{p l}$ ', is incremental equivalent plastic strains. The kinematic term added in the model as AISI 52100 steel represents ratcheting (continuous accumulation of plasticity) during cyclic loading. In order to stabilise the ratcheting response, isotropic term was added so that a realistic response towards saturation can be obtained.

Recall from Fig. 3d that the virgin material hardness can be obtained at a depth far off Hertzian contact which was found to be around $853 \mathrm{HV}(9.01 \pm 0.1 \mathrm{GPa})$, and the maximum change in instrumented hardness for $6 \mathrm{GPa}$ and $4 \mathrm{GPa}$ RCF test was found to be $1.4714 \mathrm{GPa}$ and $0.789 \mathrm{GPa}$ which yielded approximately $417 \mathrm{MPa}$ and $225 \mathrm{MPa}$ flow stress. The change in flow stress under a given loading condition is attributed to the maximum change in the yield surface, $\left((\Delta \sigma y)_{\max }\right)$. This maximum change in yield surface can be integrated into the isotropic and kinematic hardening and expressed as

$\left.(\Delta \sigma y)_{\max }\right)=Q+\sqrt{\frac{2}{3}} \frac{C}{\gamma}$.

Equation (7) represents the maximum possible change in the yield surface under RCF loading and corresponds to the saturation of cyclic hardening. This total change in yield surface can be split into isotropic expansion and kinematic expansion equally as an initial assumption since no accurate cyclic data are available for AISI 52100 bearing steel as discussed earlier. This initial assumption would lead to a $50 \%$ expansion and 50\% translation of yield surface. Next step is to estimate the cyclic hardening parameter ' $\mathrm{C}$ ', which is the initial kinematic hardening modulus. From compression stress-strain curve, Fig. 2, it can be noted that once the stress in a material exceeds the yield limit, the material experiences elasticity to plasticity transition state and its elastic modulus changes (E) to the plastic modulus ' $M$ '. It is known that with an increase in the plastic strains, ' $M$ ' tends to reduce, regardless of its stress state (i.e. uniaxial or triaxial) and eventually comes to zero representing a saturation in the strain hardening. However, during transition stage from elasticity to plasticity, the rate of plastic strain accumulation is very small and plastic modulus (M) is not much different from the elastic modulus (E). Therefore, it is safe to say that the parameter ' $\mathrm{C}$ ' which is the initial kinematic hardening modulus can be set to a value slightly smaller than $\mathrm{E}=210 \mathrm{GPa}$. With a continuous increase in the plasticity, the kinematic hardening modulus keeps on decreasing and is being governed by the factor ' $\gamma$ '. From equation (7), if the rest of the parameters are known, ' $\gamma$ ' (rate of decreasing ' $C$ ') can be easily computed.

As the total change in yield strength has been divided into isotropic and kinematic part equally, therefore it is vital to define the expansion of yield surface (Isotropic hardening) which is controlled by the hardening parameter ' $\beta$ '. This rate parameter only affects the number of cycles required for isotropic hardening hence changing the value of ' $\beta$ ' does not affect the overall hardening of the material. However, to reduce the number of RCF cycles for lesser simulation run time, a constant value of ' $\beta$ ' has been fixed initially. As an initial assumption, 50\% isotropic and 50\% kinematic hardening contribution was agreed to the total extent of hardening and corresponding cyclic hardening parameters are listed in Table 2. Previous studies $[30,39]$ have shown that in 
combined hardening models, $90 \%$ of hardening is associated with kinematic hardening. However, in kinematic hardening mode, multiple back-stress tensors are required which creates complexities during parameters estimation. The initial assumption of combined hardening in the current study provides preliminary understanding due to the absence of any known cyclic hardening parameters. The cyclic hardening parameters for $4 \mathrm{GPa}$ RCF test are also estimated and given in Table 2.

\section{Result \& Discussion}

The newly developed Finite Element Model (FEM) simulates the RCF stress cycles as the load moves from right to the left end of the domain, as shown in Fig. 5. Simulations were conducted employing a semi-empirical NIKH material model (cyclic hardening parameters listed in Table 2) and power-law hardening model (uniaxial compression flow curve, Fig. 2). The material model follows the J2-based plasticity criteria. As load moves from right to left in the 3D domain, marked as RD (rolling direction), the material undergoes yielding resulting in a subsurface plasticity zone at the centre of contact track. The initial RCF cycles have been simulated to ramp the load gradually so that a uniform stress distribution can be obtained under the contact track.

The plastic strains at subsurface lead to the plasticityinduced residual stresses in a 3-dimensional state. With repeated RCF cycles, the cyclic stress-strain loop stabilises and reaches a steady-state indicating plastic shakedown. Fig. 6a and b represents a stabilised hysteresis loop obtained for power-law hardening model and NIKH material

Table 2 Cyclic hardening parameters listed for Kine $50 \%$ as an initial estimation

\begin{tabular}{llllll}
\hline Resultant Load $\left(\mathrm{F}_{\mathrm{R}}\right)$ & $\begin{array}{l}(\Delta \sigma \mathrm{y})_{\max } \\
\text { MPa }\end{array}$ & $\mathrm{Q}$ & $\mathrm{C}$ & $\gamma$ & $\beta$ \\
\hline High $(857 \mathrm{~N})$ & 417.16 & 208.58 & 200000 & 782.91 & 50 \\
Low $(265 \mathrm{~N})$ & 225.1 & 112.55 & & 1450.9 & \\
\hline
\end{tabular}

model, respectively. Each hysteresis loop is plotted for shear stress and shear strain components at a representative depth of maximum stress state. The number of cycles required to achieve the steady-state response of the hysteresis loop depends upon the loading behaviour and the cyclic hardening parameters. For the semi-empirical numerical model used in this study, the stabilised hysteresis loop was obtained after 5 contact cycles, whereas, for power-law hardening model, it was obtained after 3 contact cycles. The reason for such early plastic shakedown at $6 \mathrm{GPa}$ is attributed towards the initial assumption of $50 \%$ isotopic/kinematic hardening contribution.

Result obtained after a few RCF cycles were acquired for a high load of $857 \mathrm{~N}$ and are presented in Fig. 7a and b. Fig. 7a represents the von Mises stress plotted with equivalent plastic strains for multiple load cycles operated under NIKH material model. The von Mises stresses continue to increase with increasing load and then start to saturate after a few load cycles as defined by the hardening parameters of the constitutive model. It can be noted that after first rolling pass, the area under contact track (subsurface region) accumulates a considerable amount of plasticity and then it starts to saturate once the stabilised cyclic stress-strain loop is achieved. A stabilised cycle is obtained just after four rolling cycles, where no further plasticity is generated under same RCF loading. The von Mises response (Fig. 7a) during rolling passes shows the generation of residual stress along with plasticity which cumulates with each rolling pass and its build-up tend to cease. The accumulation of plasticity in each load cycle in the presence of mean stress is termed ratcheting. The ratcheting phenomenon causes residual stress to relax. However, beyond shakedown limit the stress relaxation is minimal due to low plasticity damage as discussed earlier in the previous section, until softening of the material happens after hundreds of millions of RCF cycles. However, due to the limited scope of this research, such material response has been excluded in modelling and will be added as future work. Fig. 7a reports the potential generation of residual stress (RS) below the contact path which was found to be distributed below the contact path in the circumferential and tangential direction; however, the maximum
Fig. 5 (a) Direction of loading in $3 \mathrm{D}$ domain and plasticity displayed in a cylindrical coordinate system denoted as 11: radial, 22: circumferential and 33 as tangential direction. (b) Octahedral shear stress represented in a circumferential plane sliced through the centre of contact track (a)

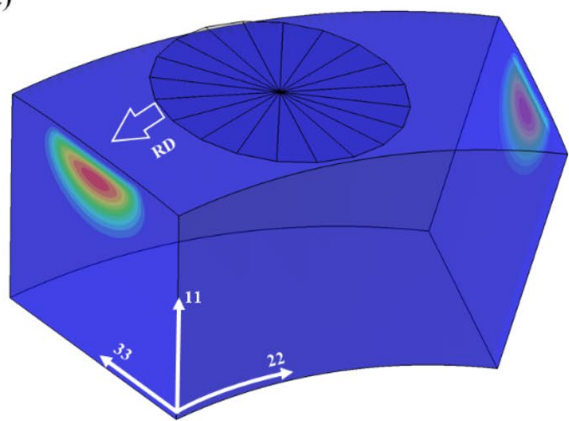

(b)

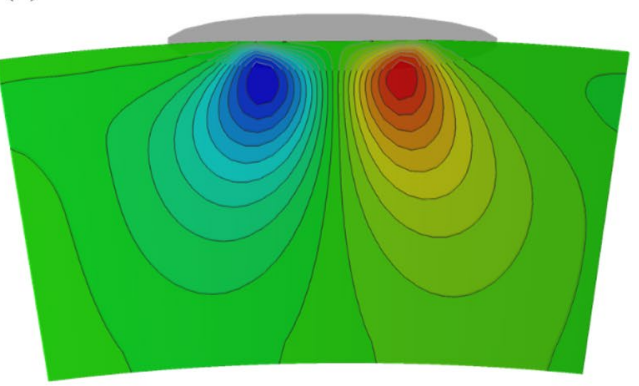


(a)

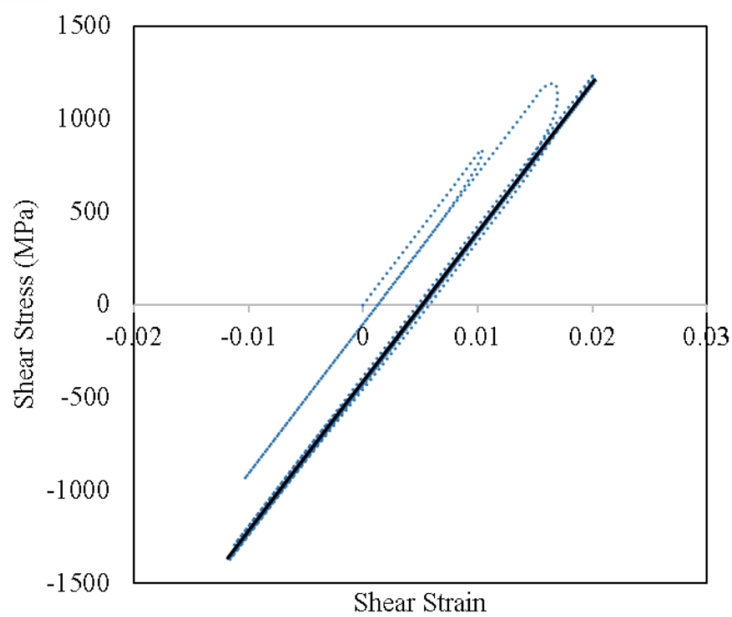

(b)

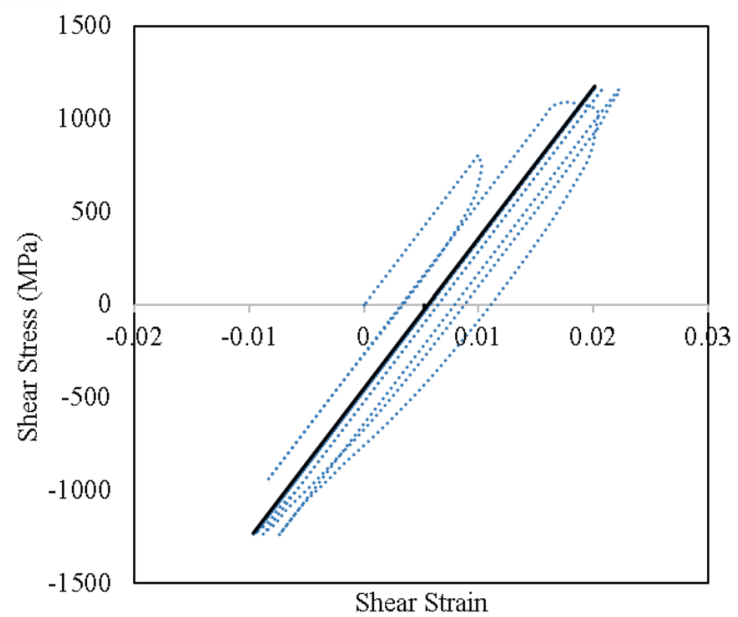

Fig. 6 Shear stress-strain cycle obtained for (a) power-law hardening and (b) NIKH material model; the steady-state hysteresis loop is represented by black solid lines

Fig. 7 Accumulation of plastic strains with (a) von Mises stress (b) Maximum orthogonal shear stress at representative depth below contact track (a)

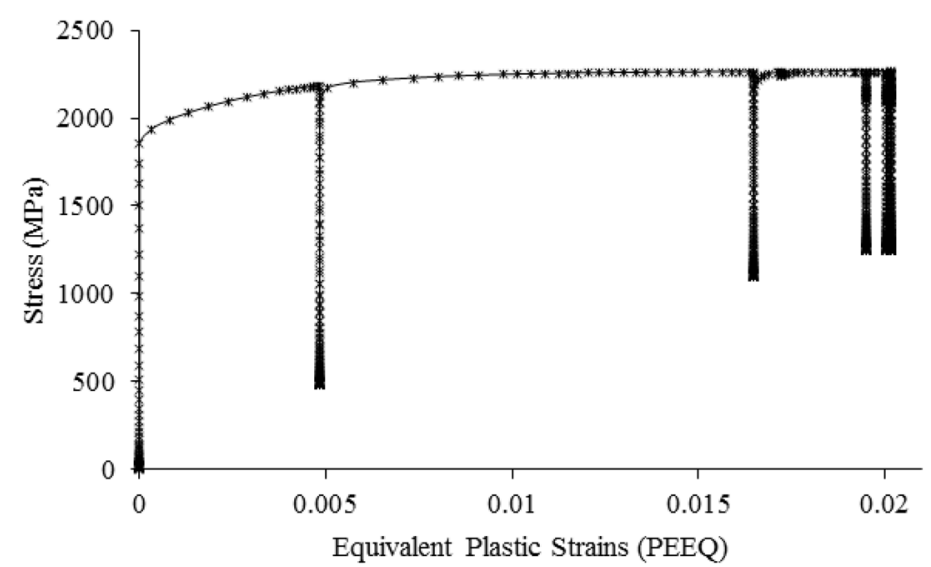

(b)

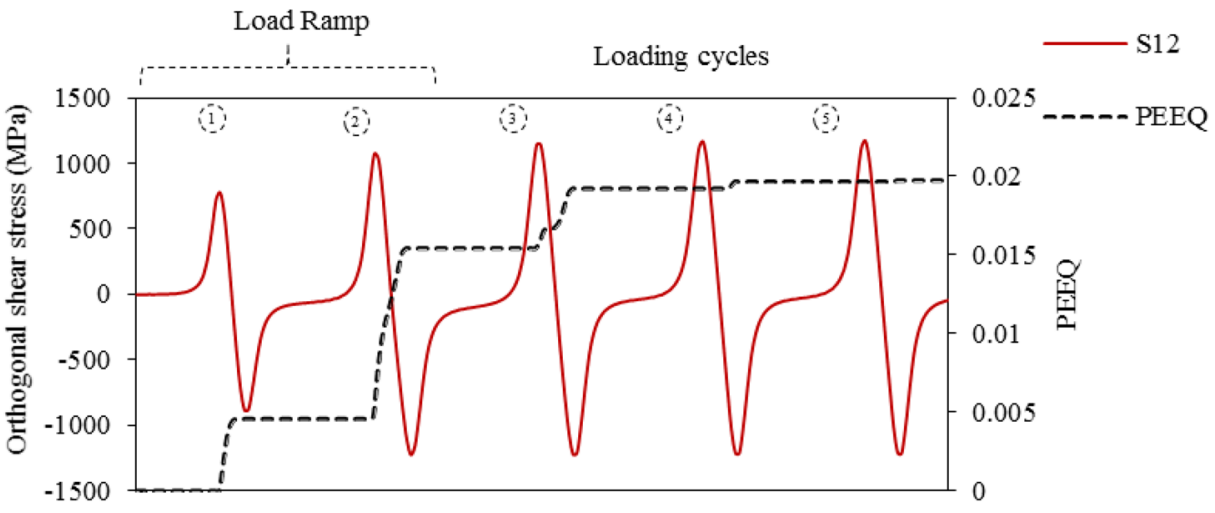

of the RS distribution was observed at centreline contact path. Fig. $7 \mathrm{~b}$ depicts the maximum orthogonal shear stress experienced by an element at a depth $\mathrm{z} / \mathrm{b}=0.48$ (represents normalised centreline depth) with plastic strains growth. It is important to know that the plastic strains accumulate in each cycle where reversal of orthogonal shear stress takes place until shakedown and there is little to no accumulation of plasticity in the following cycles.

After load removal, the residual stresses and contact track geometries were investigated. The contact track results 
obtained from the finite element model and 4-ball test are listed in Table 3 for comparison. Contact track semi-major axis observed from interferometer at both loading condition was found close to the NIKH material model in comparison with elastic (Hertzian theory) and elastoplastic model (power-law hardening). Table 3 also shows the maximum contact stress obtained from analysis which was found to be nearly the same for low resultant load of $265 \mathrm{~N}$; however, a significant difference was noticed at a high resultant load of $857 \mathrm{~N}$. Power-law hardening model and NIKH hardening model showed $5605 \mathrm{MPa}$ and $5414 \mathrm{MPa}$, respectively. The difference in the obtained contact stresses is attributed to the contact track plastic deformation and resulting track widening. The obtained half-width radius 'a' from numerical and experimental findings is listed where the value found by NIKH model was observed closer to the experimental results.

During RCF cycles, bearing material undergoes multiaxial loading, resulting in subsurface plastic damage and contact track widening. This damage is being accumulated over millions of cycles and can be related to early life and later life of the bearing material. Contact track profile measured after RCF test results from cyclic deformation due to
RCF loading. A 2D profile acquired normal to the contact track represents the maximum change in contact track profile (width and depth). Fig. 8a represents the interferometer results obtained for $6 \mathrm{GPa}$ contact stress after 0.37 million and 42.75 million RCF cycles and compared with the FEM results. It can be seen that the contact track profile obtained after 0.37 million cycles corroborates with the power-law hardening model representing a potential early life plastic shakedown of contact track. Moreover, the contact track profile obtained after 42.75 million cycles corresponds with the combined NIKH hardening model which endorses that the combined hardening model can better estimate the later life bearing material elastoplastic behaviour. In order to verify this argument, the newly developed finite element model was extended to the $4 \mathrm{GPa}$ contact stress with corresponding hardening parameters listed in Table 2 . The plastic deformation at contact track was obtained once the elastic-plastic shakedown is attained in the simulation. Fig. $8 \mathrm{~b}$ represents the contact track profiles for experimental analysis as well as simulation from combined material model. It can be seen that the experimental curve fitted well in the range of the experimental observation after 37.5 million RCF cycles under $3980 \mathrm{MPa}$ true contact pressure (Table 3). The close

Table 3 Contact track numerical and experimental analysis

\begin{tabular}{|c|c|c|c|c|c|c|c|c|c|}
\hline Parameters & & $\begin{array}{l}\text { Analytical } \\
\text { (Elastic } \\
\text { Theory) }\end{array}$ & $\begin{array}{l}\text { Power-law } \\
\text { hardening } \\
\text { Model }\end{array}$ & $\begin{array}{l}\text { NIKH } \\
\text { Hardening } \\
\text { Model }\end{array}$ & $\begin{array}{l}\text { Experimen- } \\
\text { tal observa- } \\
\text { tion }\end{array}$ & $\begin{array}{l}\text { Analytical } \\
\text { (Elastic } \\
\text { Theory) }\end{array}$ & $\begin{array}{l}\text { Power-law } \\
\text { hardening } \\
\text { Model }\end{array}$ & $\begin{array}{l}\text { NIKH } \\
\text { Hardening } \\
\text { Model }\end{array}$ & $\begin{array}{l}\text { Experi- } \\
\text { mental } \\
\text { observa- } \\
\text { tion }\end{array}$ \\
\hline $\begin{array}{l}\text { Resultant load } \\
\text { (N) }\end{array}$ & & 265.36 & & & & 857.11 & & & \\
\hline $\begin{array}{l}\text { Max. Pressure } \\
(\mathrm{MPa})\end{array}$ & & 4078.01 & 4130 & 3980 & & 6027 & 5605 & 5414 & 0.3495 \\
\hline \multirow{2}{*}{$\begin{array}{l}\text { Half width } \\
(\mathrm{mm})\end{array}$} & Major & \multirow[t]{2}{*}{0.176} & 0.1818 & 0.2074 & \multirow[t]{2}{*}{0.21} & \multirow[t]{2}{*}{0.2605} & 0.2935 & 0.3375 & \\
\hline & Minor & & 0.1680 & 0.1968 & & & 0.2631 & 0.2448 & \\
\hline
\end{tabular}

(a)

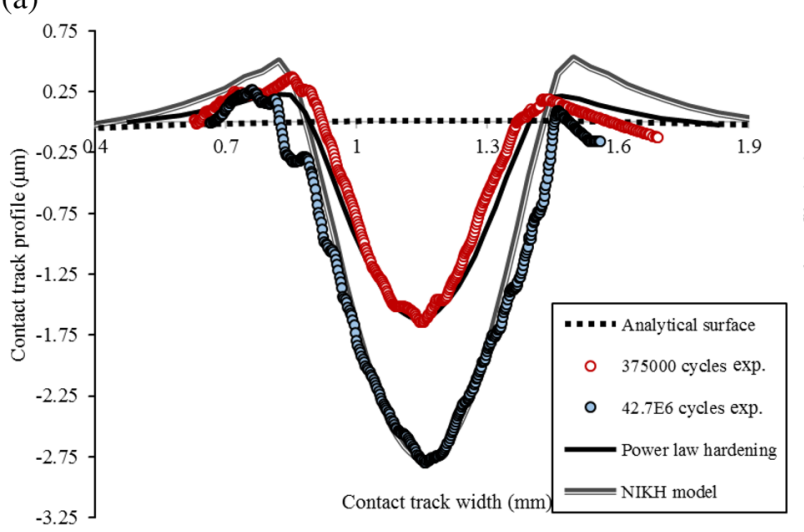

(b)

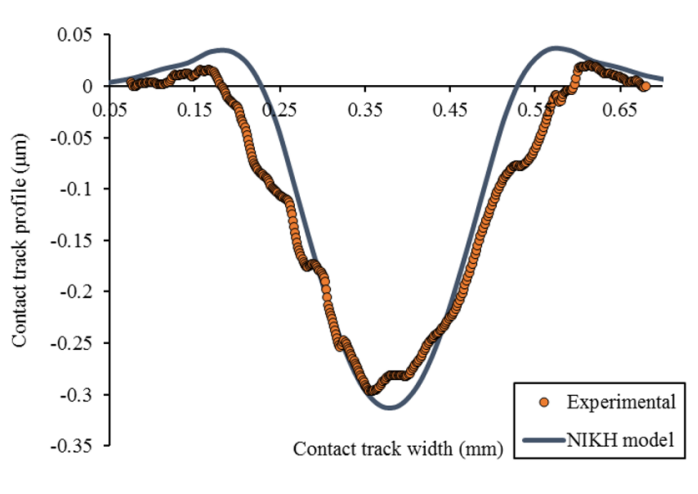

Fig. 8 Contact track profiles obtained from FEM models and RCF test conducted at (a) 6 GPa and (b) 4 GPa contact stress 
agreement and consistency of plastic deformation at contact track observed from experimental and simulation provides a linkage to the RCF subsurface damage and resulting continuously evolving residual stresses generation in the later stages of RCF life cycles.

Once the cyclic hardening parameters are testified for combined hardening model, the next step is to evaluate the cyclic hardening parameters which can best describe the evolved elastoplastic behaviour of bearing steel. The initial assumption of $50 \%$ kinematic hardening contribution in the total hardening can be varied and resulting contact track plasticity can be analysed. Table 4 lists a change in kinematic hardening contribution to $10 \%, 50 \%$ and $70 \%$ of the total hardening and resulting values of $\mathrm{Q}, \mathrm{C}$ and $\gamma$ are updated. Fig. 9a represents the contact track plasticity obtained from the variation in cyclic hardening parameters and compared with the experimental data. A $10 \%$ contribution of the kinematic hardening results in a maximum contribution of isotropic hardening which resists plasticity by a linear expansion of yield surface. Resulting contact

Table 4 Evaluation of cyclic hardening parameters

\begin{tabular}{llllll}
\hline $\begin{array}{l}(\Delta \sigma \mathrm{y})_{\max } \\
(\mathrm{MPa})\end{array}$ & Combined Hardening & $\begin{array}{l}\mathrm{Q} \\
(\mathrm{MPa})\end{array}$ & $\begin{array}{l}\mathrm{C} \\
(\mathrm{MPa})\end{array}$ & $\gamma$ & $\beta$ \\
\hline 417.16 & Kine10\%_$\beta 50$ & 375.44 & 200000 & 3914.55 & 50 \\
417.16 & Kine50\%_ $\beta 50$ & 208.58 & 200000 & 782.91 & 50 \\
417.16 & Kine70\%_ $\beta 50$ & 125.15 & 200000 & 559.22 & 50 \\
417.16 & Kine70\%_ $\beta 15$ & 125.15 & 200000 & 559.22 & 15 \\
225.1 & Kine70\%_$\beta 15$ & 67.53 & 200000 & 1036.36 & 15 \\
\hline
\end{tabular}

(a)

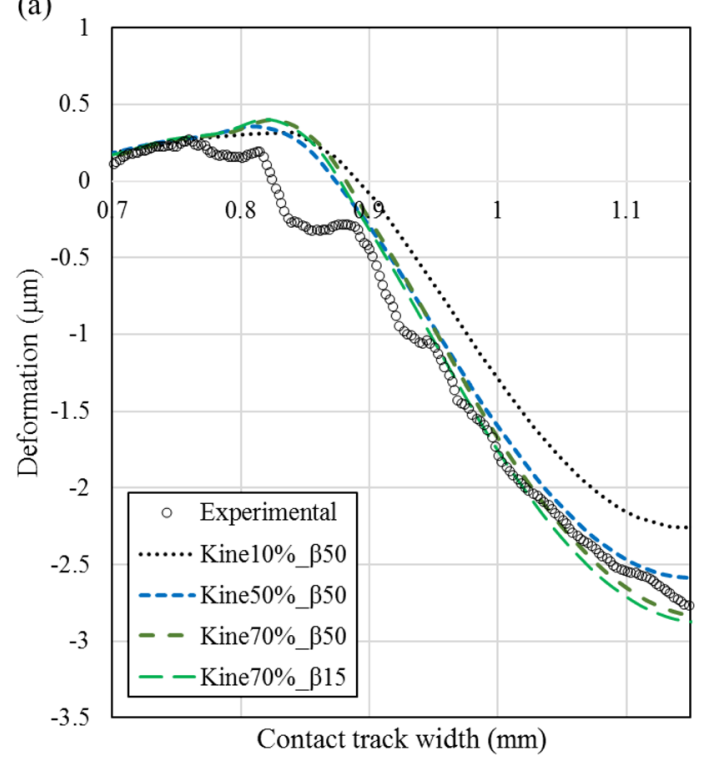

track profile is plotted as Kine $10 \%$ and is found quite low as compared to the experimental curve, whereas a $50 \%$ and $70 \%$ kinematic hardening curve lies in the vicinity of experimental data. It should be noted that these simulations are carried out with a fixed value of $\beta=50$, which defines the rate of isotropic expansion. Changing the $\beta$ value for current simulations affects the cycles required for plastic shakedown. A lower $\beta=15$ results in slightly higher plasticity accumulation (PEEQ) as observed in Fig. 9b, however, requires a considerably higher computational time in terms of stress cycles required for plastic shakedown. It was noted that a large value of $\beta$ results in lower computation time with a maximum of $5 \%$ variation in contact track deformation.

Fig. 10 represents the residual stress profiles obtained from experimental and numerical observation of throughhardened bearing steel with similar composition. Residual stress component, $\sigma_{22}$, (stress component in the circumferential direction, Fig. 5a) was acquired from $4 \mathrm{GPa}$ contact stress simulations employing power-law hardening and NIKH material model (parameters listed in Table 4) and compared with the residual stresses data presented by A. P. Voskamp [9]. The extensive testing data obtained from the fatigue testing of deep groove ball bearing (DGBB) using $\mathrm{X}$-ray diffraction technique are considered to be a benchmark for residual stress estimation under RCF load. From Fig. 10, power-law hardening model showed a reduced level of the residual stress generation during rolling cycles when compared with experimental curves obtained at 1, 10 and 100 million rolling cycles, whereas the residual stress results from combined NIKH material model lies closer to the experimental data. The underprediction of residual stresses

(b)
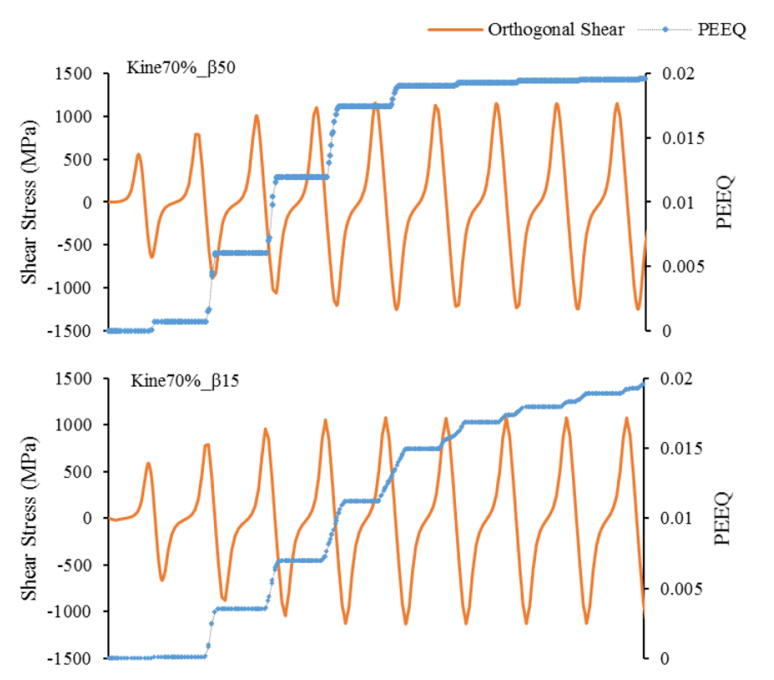

Fig. 9 Evaluation of cyclic hardening parameters: (a) Contact track profile with variation in parameters obtained for 6 GPa contact stress. (b) Effect of changing $\beta$ at subsurface plasticity accumulation 
Fig. 10 Residual stress estimation from finite element models and experimental data* obtained from RCF testing of DGBB 6309 [9] after 1, 10, 37.5 and 100 million cycles

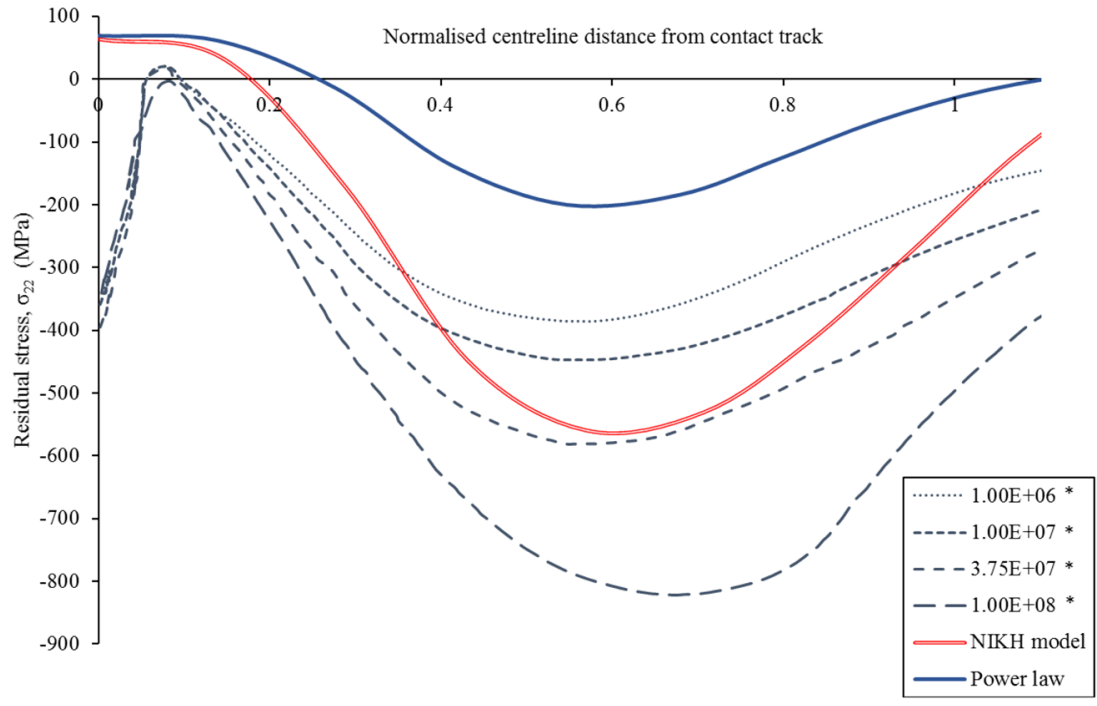

is attributed towards the elastic-plastic response caused by the power-law hardening material model which cannot mimic the cyclic hardening during rolling cycles resulting in lesser yielding of the subsurface. It can be noted that the residual stress maxima was found dissimilar for both material models. It is important to note that the residual stress data [9] plotted in Fig. 10 are reported from standard DGBB of 6309 type. The non-conformal contact in ball bearing at ball-inner raceway makes an elliptical contact which is different from a point contact of a 4-ball configuration. The difference in the osculation of contact geometries between simulated and reported experimental makes this comparison challenging which has been addressed by the normalised centreline distance. The non-linear kinematic hardening model modified with the expanding cavity model employing nanoindentation yielded a much more plausible residual stress estimation. It should be noted the NIKH residual stress profile presented in Fig. 10 corresponds to a test with 37.5 million RCF cycles at $3980 \mathrm{MPa}$ maximum contact stress so it could fall somewhere between 10 million and 100 million RS profiles obtained from DGBB test. It should be noted that the near-surface higher residual stresses in experimental data are associated with the machining processes involved to manufacture the bearing samples and were ignored during finite element analysis.

As discussed in Sect. 1, the gradual changes in residual stress during rolling cycles can be correlated to the changes in yield strength as well as to the changes in specific volume arising during microstructural alterations. The decomposition of retained austenite is associated with a volume expansion, whereas the decay of martensite is related to the volume contraction; hence, the total effect can be considered as the relative volume fraction of these phase changes. Although the microstructural phase changes progress during RCF, the bearing material undergoes considerable work hardening in the subsurface plastic zone as reported in 4-ball experimentation. The relative increase in hardness observed at $6 \mathrm{GPa}$ and $4 \mathrm{GPa}$ contact stress supports the consistency of this hardness change with progressive RCF cycles. The current study uses the change in subsurface local hardness as an indicator to estimate the gradual change in residual stress, which was not possible earlier due to the complexities of the rolling contact fatigue. Fig. 10 also shows that the residual stress profile predicted by the combined NIKH material model slightly deviates from the given experimental data. The main reason for such behaviour is the limitation of current material model which cannot take into account the decay of retained austenite resulting into internal compressive stresses and makes the residual stress profile broader at greater depths. Future work is recommended to integrate the presented FE model with the decay of retained austenite which can estimate the further development of residual stresses due to material phase transformations. Nevertheless, the close evaluation of the predicted residual stresses profiles can be seen as more profound towards greater depth at higher contact stress levels where compressive residual stresses tend to widen at greater depth. However, the normalised centreline contact path showed maxima for low and high resultant load at representative depth as shown in Fig. 11, where ' $z$ ' represents centreline distance from contact track and 'b' represents the semi-minor axis.

Recall from Sect. 1 that compressive residual stress generation under cyclic loading influences the fatigue life by altering the alternating stress amplitude especially in the later stage of RCF. To understand the change in alternating stress range driving RCF, the Mises stress profiles at centerlines contact track have been plotted for $4 \mathrm{GPa}$ and $6 \mathrm{GPa}$ contact stress in Fig. 12a and b. Maximum Mises stresses during loading state and after unloading have been shown for NIKH material model, power-law hardening and Hertzian 


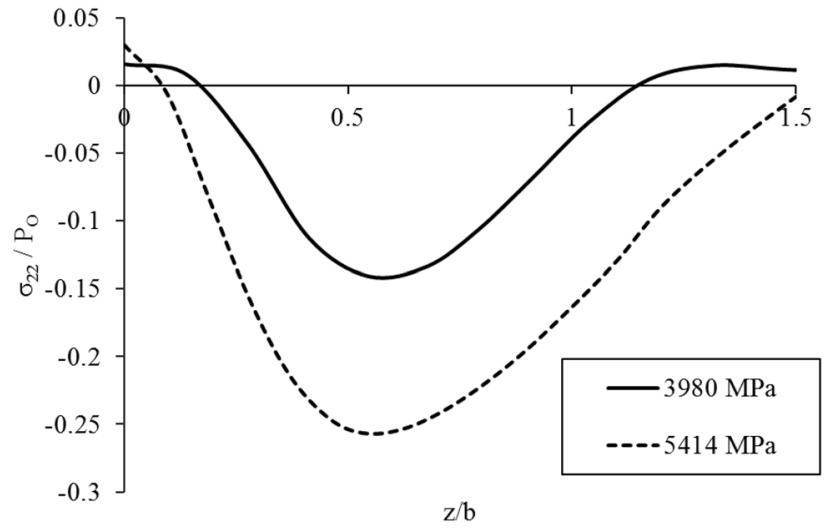

Fig. 11 Later life residual stress estimation from modified NIKH material model with corresponding true contact pressure

elastic theory. The pure elastic contact between ball-on-ball point contact for $4 \mathrm{GPa}$ contact stress has shown maxima of $2650 \mathrm{MPa}$ which is slightly reduced at $2430 \mathrm{MPa}$ employing power-law hardening model, representing initial plastic shakedown. However, the NIKH material model employed in current study has shown reduced Mises maxima of 2170 $\mathrm{MPa}$. The $11 \%$ reduction in Mises stress at critical depth, i.e. $\mathrm{z} / \mathrm{b}=0.48$, represents the evolved alternating stress (Mises) range after 37.5 million RCF cycles. Similarly, at $6 \mathrm{GPa}$ contact stress, the maxima for applied Mises stress can be found as $3930 \mathrm{MPa}, 2700 \mathrm{MPa}$ and $2040 \mathrm{MPa}$ for elastic, powerlaw and NIKH material model, respectively. The reduction in applied stress was found nearly $24 \%$ for NIKH material model. Moreover, it can be noticed that the evolved von Misses stress with the superposition of residual stress tend to shift its maxima from the critical depths to deeper or closer towards the surface. It was reported $[9,40]$ that the subsurface microstructural alterations, i.e. dark etching regions (DERs) and white etching bands (WEBs), are directly associated with the accumulation of plasticity which in turn related to the applied alternating stress range; the evolution of such Mises stress profile also helps to retard the development of visible microstructural alterations. Recent studies $[34,36]$ have shown that microstructural alterations are governed by the maximum distortion energy yield criteria during multiaxial RCF loadings where subsurface plasticity is governed by equivalent von Mises stresses. Inclusion of deep zone residual stresses with von Mises stress profile can better explain the formation mechanism of such microstructural alterations. The continuous development and progression of DERs and WEBs for ball-on-ball point contact under $4 \mathrm{GPa}$
Fig. 12 Simulated and numerical stress profiles acquired for (a) 4 GPa contact stress and (b) $6 \mathrm{GPa}$ contact stress. Dotted lines represent microstructural alteration depth range under contact track, *obtained from 4-ball RCF testing [36], whereas the spread of these lines shows the continuous growth with progressive stress cycles (a)

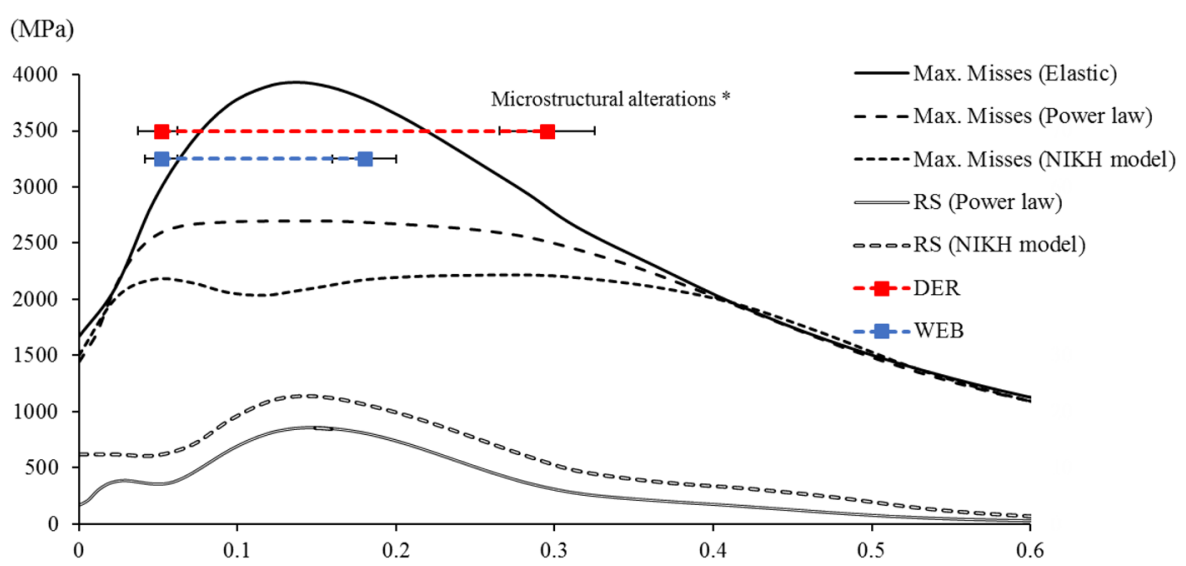

(b)

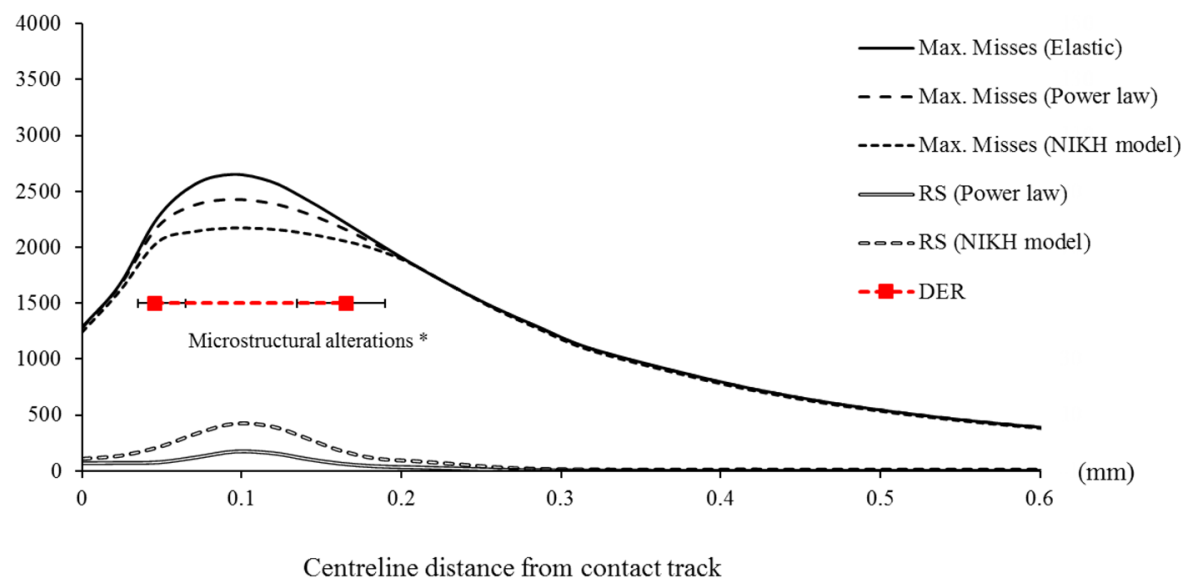


and $6 \mathrm{GPa}$ contact stress are obtained from [36] and plotted in Fig. 12. The spread of dotted lines represents the development of minimum and maximum depth of microstructural alterations from a few million cycles to tens of million cycles. It can be seen that the wider spread of von Mises maxima with progressive RCF cycles corroborates well with formation of DERs which is comparable from a recent study [36]. With the subsurface plasticity accumulation, lowering of von Mises stress profile indicates lowering of yield stress which coincides with the depth range of WEBs formation. Fu et al. [40] has stated the ferrite bands within WEBs manifest the accumulated plastic strains (PEEQ) and its reported value is 0.01863 which is quite close to our current FEM results. It should be noticed that no WEBs were observed in current study due to low operating temperatures, i.e. $40^{\circ} \mathrm{C}$, as thermal diffusivity of Carbon can significantly affect the formation of WEBs as discussed in previous studies [36, 41]. Nevertheless, the evolved Mises criteria can define the evolution of microstructural alterations in well agreement with the experimental data [36] and can be used to develop formation models for DERs.

It is evident from Fig. 12 that the later life residual stresses play a significant role in altering alternating Mises stress for each stress levels where the significant material strain hardening governs the evolution of residual stress. This evolution of residual stress and its effects on mean stress can be understood with a modified Goodman approach [42], where the residual stress affects the mean stress levels with the relation as $\frac{S_{\max }-S_{\min }}{2}+R S$, where $S_{\max }$ and $S_{\min }$ represent the maximum and minimum amplitude of alternating stress in RCF. The presence of subsurface residual stresses along with mean stress is extremely beneficial and hence optimum microstructural design for significant work hardening of bearing material and resulting compressive residual stresses is a key for a prolonged service life of bearing elements. Current research work is focused on the semi-empirical approach to model RCF simulation and evaluating subsurface plasticity-induced residual stresses and highlights its importance to increase the fatigue life of bearing elements in operation and understanding microstructural alterations. The novelty of the current study lies in the methodology to carry out this scientific research where only four cyclic hardening parameters are required to accurately capture the evolved bearing material response. The combined hardening model (NIKH) employed in the current study incorporates the isotropic expansion and non-linear kinematic hardening of a bearing material operated under RCF. In order to obtain the cyclic hardening parameters, a three-faced pyramidal Berkovich nanoindenter has been used to evaluate the subsurface yield stresses in terms of instrumentation hardness (GPa) which evolves gradually with progressive RCF cycles. The precise spatial evaluation of the very localised hardness change and the integration of the expanding cavity model facilitates the analysis of evolved subsurface yield stresses which were then employed into FEM simulations. The constitutive material constants employed in the current study are obtained directly from the RCF-tested bearing samples which represent the true elastic-plastic nature of evolved bearing steel which makes the current model more feasible and viable to apply in industrial research and applications. Furthermore, the semi-empirical material model can be coupled with continuum damage mechanics to investigate the failure and degradation of the material. This is significant in terms of design for the durability of bearing elements.

\section{Conclusions}

A comprehensive finite element model has been developed for evolved bearing material elastoplastic response, prediction of plasticity-induced deep zone residual stresses and subsequent effects on microstructure. For RCF testing, standard AISI 52100 bearing steel balls have been tested in a rotary tribometer at $4 \mathrm{GPa}$ and $6 \mathrm{GPa}$ contact stress. PostRCF subsurface analysis has been conducted to obtain the hardening response of the bearing material. This research concludes the subsequent key points:

- The subsurface microscopic investigation has revealed substantial microstructural alterations at $6 \mathrm{GPa}$ contact stress, whereas no considerable microstructural changes were observed at $4 \mathrm{GPa}$. Nanoindentation analysis of the RCF-tested samples revealed a significant change in subsurface hardness. For both contact stresses, substantial work hardening of bearing material was observed at representative depths.

- The cyclic hardening parameters were estimated with instrumented hardness measurement of the evolved subsurface in conjunction with the expanding cavity model. The cyclic hardening parameters were estimated for combined non-linear isotropic kinematic hardening (NIKH) behaviour and employed in newly developed 3D finite element model to mimic the cyclic hardening of rolling contact fatigue.

- The modelling results for contact track profiles and residual stresses revealed that the simplistic power-law hardening model can estimate the early plastic shakedown of RCF, whereas the combined NIKH hardening model corroborates well with the elastoplastic behaviour in the later stages of RCF stress cycles.

- Microplasticity-induced residual stresses showed a significant effect on the alternating Mises stress range. The 11\% and 24\% reduction of Mises stress just after few tens of million cycles shows the evolution of subsurface material response under RCF. The inclusion of deep zone residual stress with the von Mises stress criteria explain the progres- 
sion of microstructural alterations and can be extended to develop the prognostic models for DER/WEB formation.

- The quantitative model for plasticity-induced residual stress generation employed in the current study minimises the complexities of RCF modelling and can be applied to any through-hardened bearing steel.

Acknowledgements The authors would like to acknowledge Schaeffler Technologies AG \& Co, KG, Germany for their direct funding (Grant ID: 10187) and in-kind support for conducting this research at Bournemouth University, United Kingdom.

Open Access This article is licensed under a Creative Commons Attribution 4.0 International License, which permits use, sharing, adaptation, distribution and reproduction in any medium or format, as long as you give appropriate credit to the original author(s) and the source, provide a link to the Creative Commons licence, and indicate if changes were made. The images or other third party material in this article are included in the article's Creative Commons licence, unless indicated otherwise in a credit line to the material. If material is not included in the article's Creative Commons licence and your intended use is not permitted by statutory regulation or exceeds the permitted use, you will need to obtain permission directly from the copyright holder. To view a copy of this licence, visit http://creativecommons.org/licenses/by/4.0/.

\section{Appendix}

\section{Indenter Tip Calibration}

The projected contact area ' $A$ ' for an ideal Berkovich can be described in terms of contact depth $(h)$ and semi angle $(\theta)$ as

$A=3 \sqrt{3} h^{2} \tan ^{2} \theta$

In general, indenter tips are slightly rounded around the apex and require a depth-area function relation at lower depths. The indenter area function in current study is determined by a range of depth indentation performed at a known homogenous material fused silica with hardness around 9-10 GPa and reduced modulus nearly 69-70 GPa.

After indentation, the pyramidal area is obtained from described relation and plotted with measured depth as shown in Fig. A1. The relationship between projected contact area and plastic depth is known as diamond area function (DAF):

$D A F=-0.0015 x^{3}+23.017 x^{2}+960.87 x-71583$.

Once the DAF of the indenter tip is obtained, nanoindentation can be performed at bearing steel samples and respective localised hardness can be obtained from method illustrated in Sect. 2.1.

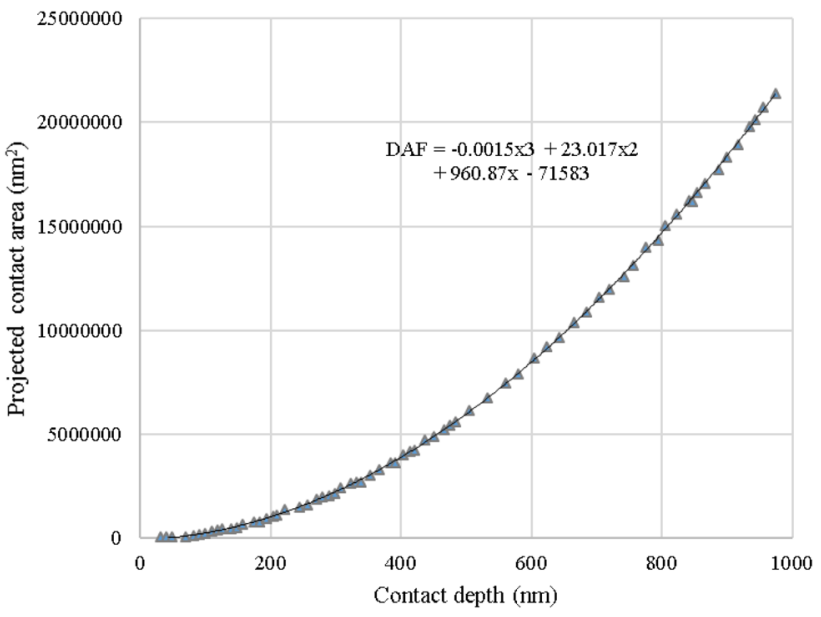

Fig. 13 Projected contact area plotted against contact depth

\section{Lambda Ratio Calculations}

The lambda ratio $(\lambda)$, also known as specific film thickness, can be calculated for spherical bodies under Hertzian contact by [43];

$\lambda=\frac{\mathrm{h}_{\min }}{\sqrt{2 \mathrm{r}_{\mathrm{rms}}^{2}}}$,

where

$\mathrm{h}_{\min }=3.63 \mathrm{R}^{\prime} \mathrm{U}^{0.68} \mathrm{G}^{0.49} \mathrm{~W}^{-0.073}\left(1-\mathrm{e}^{-0.68 \mathrm{k}}\right)$.

$\mathrm{U}=\frac{\eta_{\mathrm{o}} \mathrm{u}}{\mathrm{E}^{\prime} \mathrm{R}^{\prime}}$

$\mathrm{G}=\alpha \mathrm{E}^{\prime}$

$\mathrm{W}=\frac{\mathrm{F}}{\mathrm{E}^{\prime} \mathrm{R} \prime^{2}}$

Here $\mathrm{k}, \eta_{\mathrm{o}}, \mathrm{u}, \mathrm{E}^{\prime}, \mathrm{R}^{\prime}, \alpha, \mathrm{F}, \mathrm{r}_{\mathrm{rms}}$ represent ellipticity ratio, atmospheric viscosity, mean speed, reduced elasticity, effective radius, viscosity-pressure coefficient, normal load and surface roughness, respectively.

Rotational speed $=4300 \mathrm{rpm}$

Lubricant: ISO Vg-320, $320 \mathrm{cSt}(320 \mathrm{~mm} 2 / \mathrm{sec})$ at $40^{\circ} \mathrm{C}$, $32.7 \mathrm{cSt}(32.7 \mathrm{~mm} 2 / \mathrm{sec})$ at $100{ }^{\circ} \mathrm{C}$

Density $=0.86 \mathrm{~g} / \mathrm{ml}$ at $20^{\circ} \mathrm{C}$

Pressure viscosity coefficient, $\alpha=13 \mathrm{GPa}^{-1}$ at $40{ }^{\circ} \mathrm{C}, 9$ $\mathrm{GPa}$ at $100^{\circ} \mathrm{C}[44]$

Modulus of elasticity, $\mathrm{E}=210 \mathrm{GPa}$, Poison's ratio, $\mathrm{v}=$ 0.3

Average surface roughness of tested samples $=r_{\text {rms }}=$ $0.0109 \pm 0.002 \mu \mathrm{m}$ 
Minimum film thickness $=0.41 \mu \mathrm{m}$

Lambda ratio $=26.1$

The specific film thickness obtained at $6 \mathrm{GPa}$ Contact pressure and $40{ }^{\circ} \mathrm{C}$ operating temperature shows a full fluid film lubrication between upper ball and lower balls in contact.

\section{References}

1. Kang, J.H., Hosseinkhani, B., Rivera-Díaz-del-Castillo, P.E.J.: Rolling contact fatigue in bearings: multiscale overview. Mater. Sci. Technol. 28(1), 44-49 (2012)

2. Sadeghi, F., et al.: A review of rolling contact fatigue. J. Tribol. 131(4), 041403 (2009)

3. Arakere, N.K.: Gigacycle rolling contact fatigue of bearing steels: a review. Int. J. Fatigue. 93, 238-249 (2016)

4. Reid, A., et al.: Measurement of strain evolution in overloaded roller bearings using energy dispersive $\mathrm{X}$-ray diffraction. Tribol. Int. 140, 105893 (2019)

5. Hahn, G., et al.: Analysis of the rolling contact residual stresses and cyclic plastic deformation of SAE 52100 steel ball bearings. J. Tribol. 109(4), 618-626 (1987)

6. Klecka, M.A., Subhash, G., Arakere, N.K.: Microstructure-property relationships in M50-NiL and P675 case-hardened bearing steels. Tribol. Trans. 56(6), 1046-1059 (2013)

7. Hahn, G., Bhargava, V., Chen, Q.: The cyclic stress-strain properties, hysteresis loop shape, and kinematic hardening of two highstrength bearing steels. Metall. Mater. Trans. A. 21(2), 653-665 (1990)

8. Warhadpande, A., et al.: Influence of plasticity-induced residual stresses on rolling contact fatigue. Tribol. Trans. 55(4), 422-437 (2012)

9. Voskamp, A., et al.: Gradual changes in residual stress and microstructure during contact fatigue in ball bearings. Met. Technol. 7(1), 14-21 (1980)

10. Khan, Z.A., et al.: Residual stress variations during rolling contact fatigue of refrigerant lubricated silicon nitride bearing elements. Ceram. Int. 32(7), 751-754 (2006)

11. Shen, Y., et al.: Effect of retained austenite - compressive residual stresses on rolling contact fatigue life of carburized AISI 8620 steel. Int. J. Fatigue. 75, 135-144 (2015)

12. Nazir, M.H., Khan, Z.A., Saeed, A.: Experimental analysis and modelling of c-crack propagation in silicon nitride ball bearing element under rolling contact fatigue. Tribol. Int. (2018)

13. Jhansale, H., Topper, T.: Engineering analysis of the inelastic stress response of a structural metal under variable cyclic strains. In: Cyclic Stress-Strain Behavior-Analysis, Experimentation, and Failure Prediction. ASTM International, West Conshohocken (1971)

14. Lindgren, M., Lepistö, T.: Effect of mean stress on residual stress relaxation in steel specimens. Mater. Sci. Technol. 18(8), 845-849 (2002)

15. Polonsky, I., Keer, L.: On white etching band formation in rolling bearings. J. Mech. Phys. Solids. 43(4), 637-669 (1995)

16. Warhadpande, A., Sadeghi, F., Evans, R.D.: Microstructural alterations in bearing steels under rolling contact fatigue part 1historical overview. Tribol. Trans. 56(3), 349-358 (2013)

17. Khan, Z.A., Hadfield, M.: Manufacturing induced residual stress influence on the rolling contact fatigue life performance of lubricated silicon nitride bearing materials. Mater. Des. 28(10), 26882693 (2007)
18. Rosado, L., et al.: Rolling contact fatigue life and spall propagation of AISI M50, M50NiL, and AISI 52100, Part I: experimental results. Tribol. Trans. 53(1), 29-41 (2009)

19. Voskamp, A.: Material response to rolling contact loading. ASME Trans. J. Tribol. 107, 359-364 (1985)

20. Morris, D., et al.: Effect of residual stresses on microstructural evolution due to rolling contact fatigue. J. Tribol. 140(6), 061402 (2018)

21. Radhakrishnan, V., Ramanathan, S.: Plastic deformation in rolling contact. Wear. 32(2), 211-221 (1975)

22. Golmohammadi, Z., Walvekar, A., Sadeghi, F.: A 3D efficient finite element model to simulate rolling contact fatigue under high loading conditions. Tribol. Int. (2018)

23. Bomidi, J.A.R., Sadeghi, F.: Three-dimensional finite element elastic-plastic model for subsurface initiated spalling in rolling contacts. J. Tribol. 136(1) (2013): 011402-011402-14

24. Li, F., et al.: A new damage-mechanics-based model for rolling contact fatigue analysis of cylindrical roller bearing. Tribol. Int. 120, 105-114 (2018)

25. Shen, F., Zhou, K.: An elasto-plastic-damage model for initiation and propagation of spalling in rolling bearings. Int. J. Mech. Sci. 161, 105058 (2019)

26. Walvekar, A.A., Sadeghi, F.: Rolling contact fatigue of case carburized steels. Int. J. Fatigue. 95, 264-281 (2017)

27. Bush, J., Grube, W., Robinson, G.: Microstructural and residual stress changes in hardened steel due to rolling contact. Trans. ASM. 54, 390-412 (1961)

28. Lemaitre, J., Chaboche, J.-L.: Mechanics of Solid Materials. Cambridge University Press, Cambridge (1994)

29. Chaboche, J.L.: A review of some plasticity and viscoplasticity constitutive theories. Int. J. Plast. 24(10), 1642-1693 (2008)

30. Pandkar, A.S., Arakere, N., Subhash, G.: Ratcheting-based microstructure-sensitive modeling of the cyclic hardening response of case-hardened bearing steels subject to Rolling Contact Fatigue. Int. J. Fatigue. 73, 119-131 (2015)

31. Gao, X.-L., Jing, X., Subhash, G.: Two new expanding cavity models for indentation deformations of elastic strain-hardening materials. Int. J. Solids Struct. 43(7-8), 2193-2208 (2006)

32. Bhattacharyya, A., et al.: Cyclic constitutive response and effective S-N diagram of M50 NiL case-hardened bearing steel subjected to Rolling Contact Fatigue. J. Tribol. 137(4), 041102 (2015)

33. Bhattacharyya, A., Subhash, G., Arakere, N.: Evolution of subsurface plastic zone due to rolling contact fatigue of M-50 NiL case hardened bearing steel. Int. J. Fatigue. 59, 102-113 (2014)

34. El Laithy, M., et al.: Further understanding of rolling contact fatigue in rolling element bearings-a review. Tribol. Int., 105849 (2019)

35. Rico, J.F., Battez, A.H., Cuervo, D.G.J.T.I.: Rolling contact fatigue in lubricated contacts. Tribol. Int. 36(1), 35-40 (2003)

36. Abdullah, M.U., Khan, Z.A., Kruhoeffer, W.: Evaluation of dark etching regions for standard bearing steel under accelerated rolling contact fatigue. Tribol. Int., 106579 (2020)

37. Oliver, W.C., Pharr, G.M.: An improved technique for determining hardness and elastic modulus using load and displacement sensing indentation experiments. J. Mater. Res. 7(6), 1564-1583 (1992)

38. Šmel,ova, V., et al.: Electron microscopy investigations of microstructural alterations due to classical Rolling Contact Fatigue (RCF) in martensitic AISI 52100 bearing steel. Int. J. Fatigue. 98, 142-154 (2017)

39. Pandkar, A.S., Arakere, N., Subhash, G.: Microstructure-sensitive accumulation of plastic strain due to ratcheting in bearing steels subject to Rolling Contact Fatigue. Int. J. Fatigue. 63, 191-202 (2014)

40. Fu, H., Rivera-Díaz-del-Castillo, P.E.J.: Evolution of white etching bands in $100 \mathrm{Cr} 6$ bearing steel under rolling contact-fatigue. Metals. 9(5), 491 (2019) 
41. Mitamura, N., H. Hidaka, and S. Takaki. Microstructural development in bearing steel during rolling contact fatigue. Mater. Sci. Forum. 2007. v539-543: 4255-4260. Trans Tech Publ.

42. Bhattacharyya, A., et al.: A new approach towards life prediction of case hardened bearing steels subjected to rolling contact fatigue. Mater. Perform. Charact. 6(4), 656-677 (2017)

43. Hamrock, B.J. and D. Dowson, Isothermal elastohydrodynamic lubrication of point contacts: part III-fully flooded results. 1977, J. Lubr. Technol., v99 n2, 264-275.
44. Vengudusamy, B., Enekes, C., Spallek, R.: EHD friction properties of ISO VG 320 gear oils with smooth and rough surfaces. Friction. 8(1), 164-181 (2020)

Publisher's Note Springer Nature remains neutral with regard to jurisdictional claims in published maps and institutional affiliations. 